The Role of Media in implanting Education Values in Iraqi Child

Researcher Thanaa Mutalib Hoisin

Thanaa_1212@yhoo.com

Noah Izzidden Al-Salihi

University of Baghdad- College of Media

DOI: $10.31973 / a j \cdot v 2 i 137.1638$

\begin{abstract}
:
Our current research aims to know the role of the media in implanting the educational values of the Iraqi child. This is after the media; the way the child communicates with the surrounding community. They help him to interact properly, create creativity, and improve learning. Social media networks work to attract children as they are new and unconventional networks. Because it encourages the shy and lonely to express themselves easily and easily. In order to reach to verify the objectives and hypotheses of the research. The researchers identified a set of educational values, totaling (14) educational values, which the media work to instill in children according to what has been mentioned in the previous literature. Then they built an exploratory questionnaire consisting of (34) questions, which were distributed to a sample of children aged between (11-16) years. The research sample consisted of (600) children, by (300) children of males, and (300) children of females, and after extracting validity and reliability factors for the research questionnaire. And then applying its items to the sample, the children's answers were analyzed to confirm the role of the media in implanting their educational values, and the results have shown that the media have a major role in implanting the educational values of the Iraqi child.
\end{abstract}

Key words: the media, the Iraqi child, educational values. 


\section{دور الاعلام في ترسيخ القيم التربوية لدى الطقل العراقي}

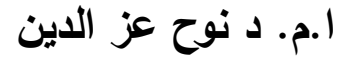 \\ جامعة بغداد/ كلية الاعلام}

الباحثة: ثناء مطلب حسين

جامعة بغداد/ كلية الاعلام

Thanaa_1212@yhoo.com

(مُلَخََّصُ البَحثث)

يهدف بحثنا الحالي معرفة دور وسائل الاعلام في ترسيخ القيم التربوية لدى الطفل

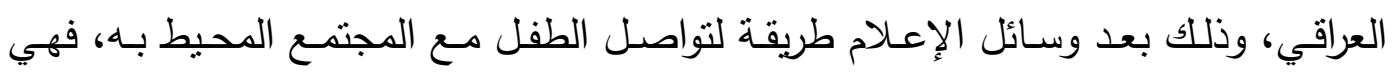

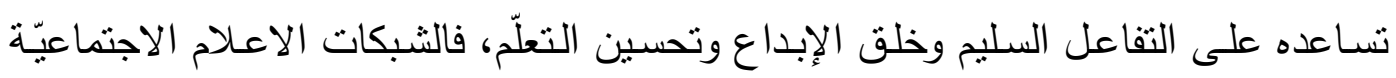

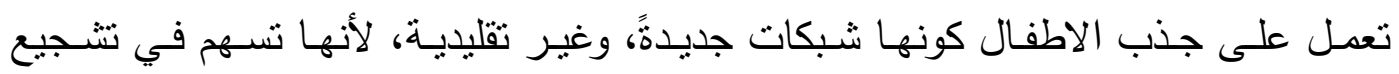

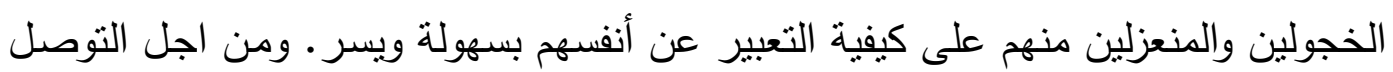

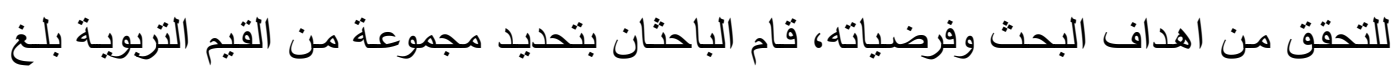

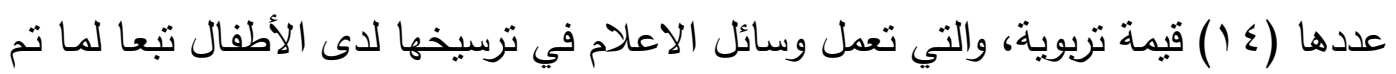

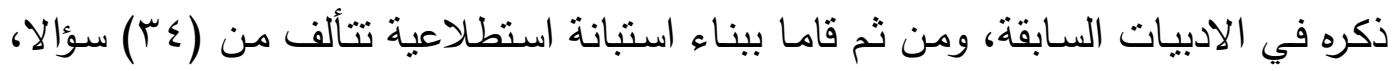

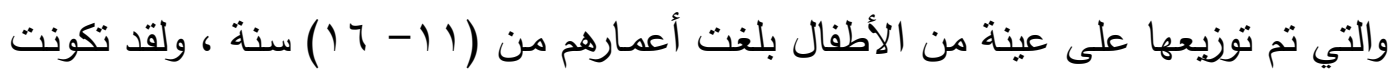

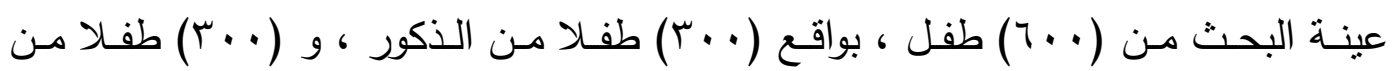

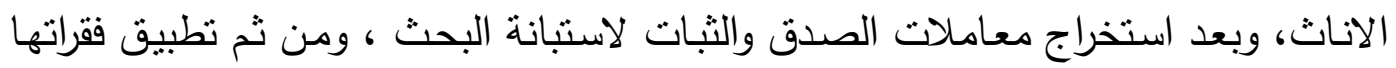

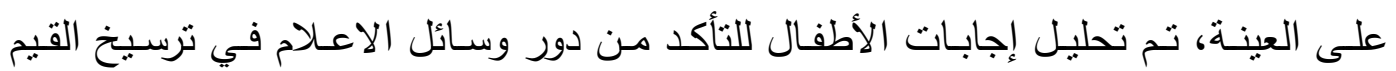

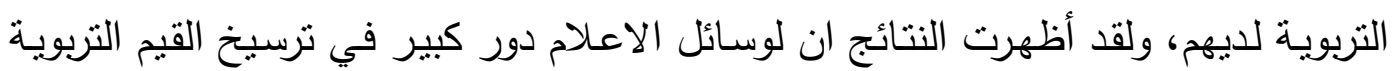

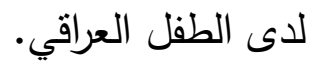
الكلمات المفتاحية: وسائل الاعلام، الطفل العراقي، القيم التربوية.

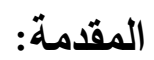

يُنظر إلى مرحلة الطفولة على انها تلك المرحلة التي تبدأ بمرحلة الرضاعة وتتنهي بدخول الإنسان بمرحلة البلوغ، وقد تم تقسيم تلك المرحلة في علم النفس التتموي إلى عدة

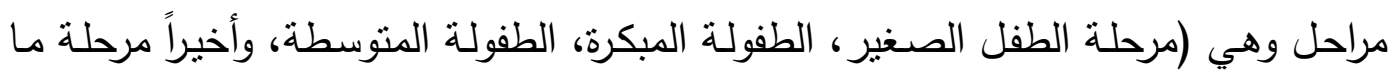

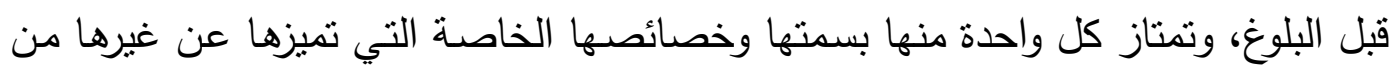

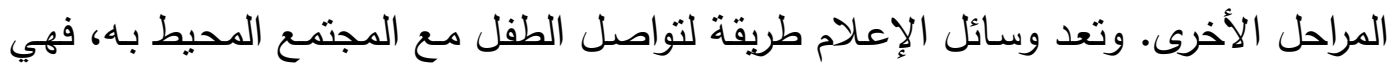

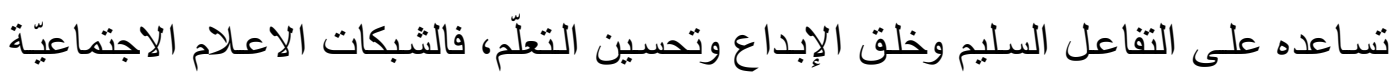

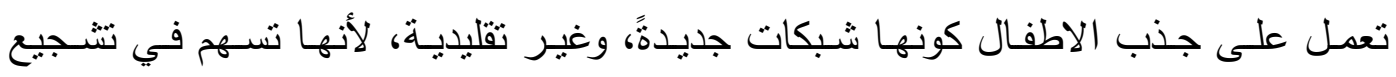


الخجولين والمنعزلين منهم على كيفية التعبير عن أنفسهم بسهولة ويسر ـ كما وتدفع بهم

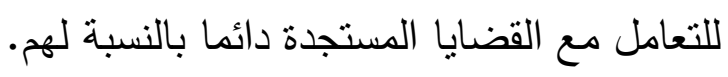

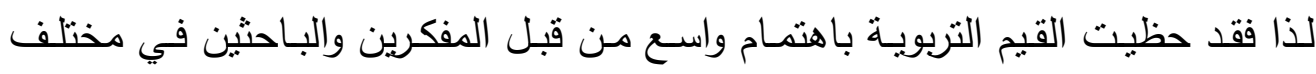

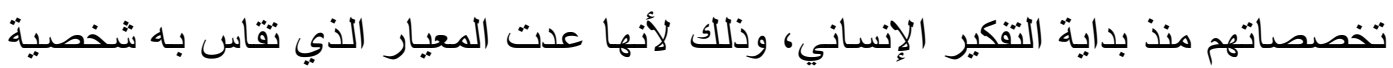

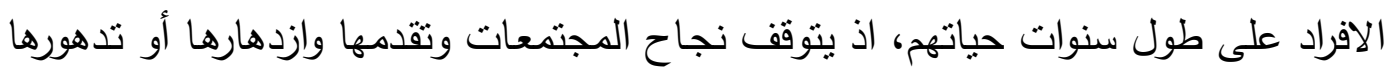

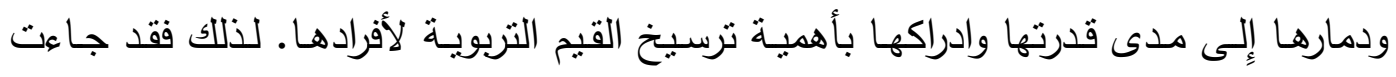
الدراسة الحالية لتسليط الضوء على دور وسائل الاعلام في ترسيخ القيم التربوية لدى الطفل

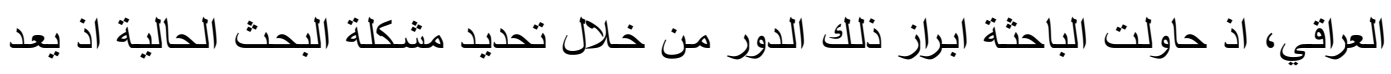

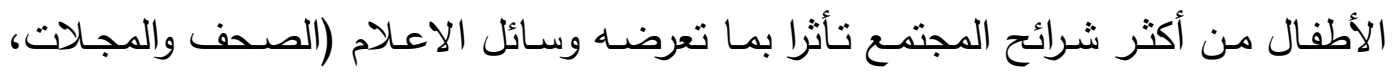

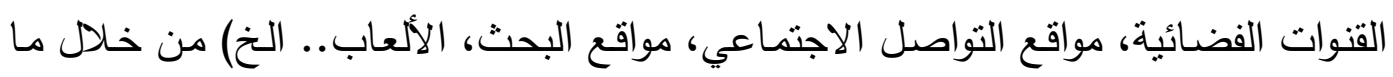
تقدمه من خدمات للطفل. الإطار المنهجي للبحث

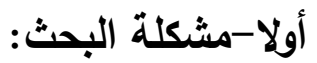

تبرز مشكلة الدراسة الحالية في معرفة الدور الذي تلعبه وسائل الإعلام في ترسيخ القيم

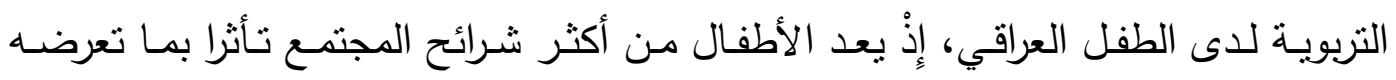

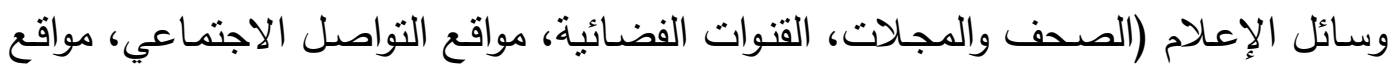

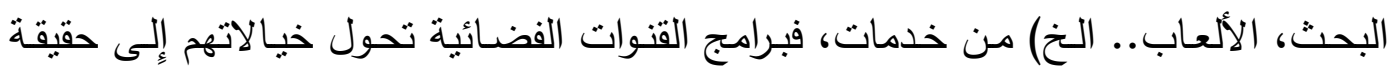

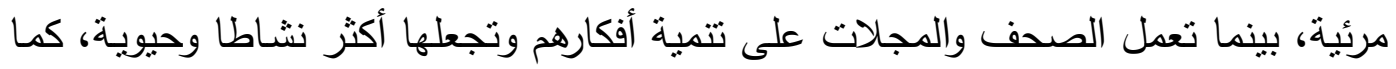

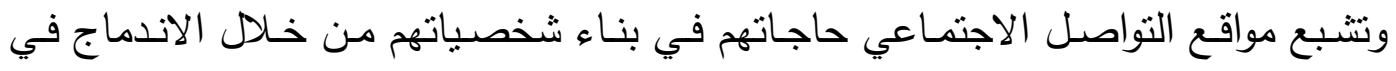

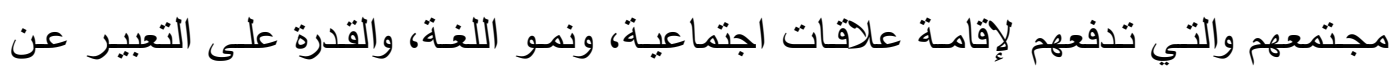

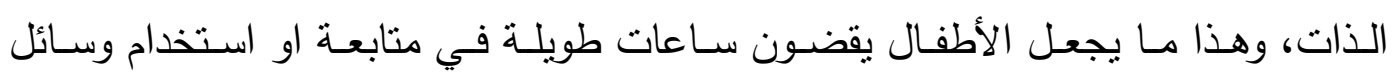

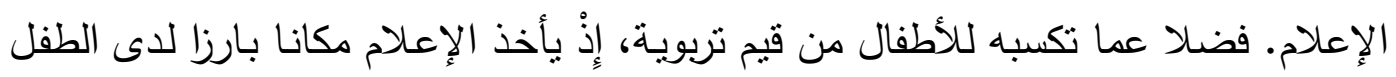

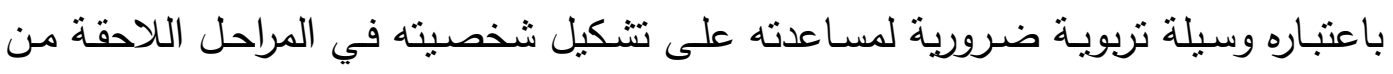
حياته، من خلال الدور الفاعل الذي بلعبه في ترسيخ بعض المبادئ والسلوكيات الإيجابية

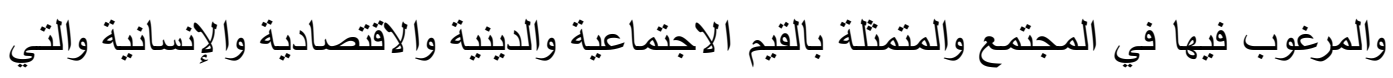

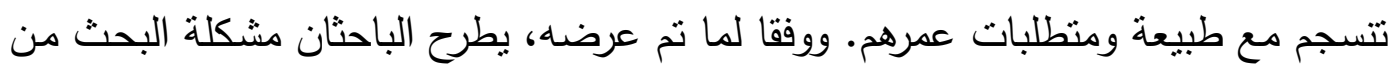
خلال ابرازها بعدد من التساؤلات والتي يسعى البحث للإجابة عنها، وكالاتي:

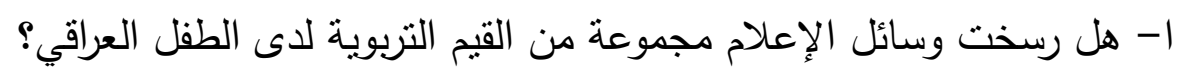

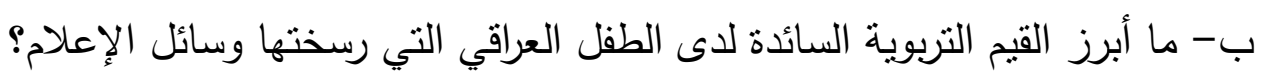


لذا تتبع أهمية البحث من خلاد ابراز الجانبين الآتيين:

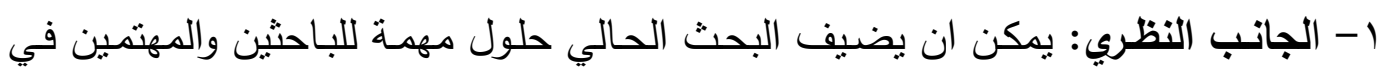
ميدان الإعلام، ولاسيما مجال الصحافة، والتي تهتم بموضوع دور وسائل الإعلام في ترسيخ القيم التزبوية لدى الطفل؛ كذلك تبرز أهمية البحث من خلال تتاوله للعينة والمتنتلة بشريحة الاطفال، ومن هنا يمكن اعتبار البحث دراسة علمية دقيقة نتنحق الدراسة والاهتمام.

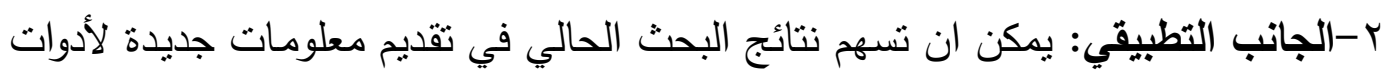

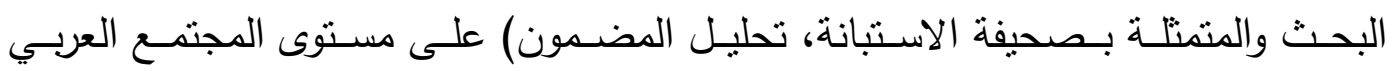

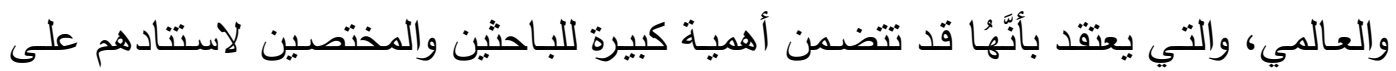
متغيرات البحث الحالي في دراسات لاحقة.

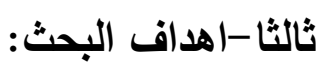

ا-نوع القيم التربوية السائدة لدى الطفل العراقي في ضوء دور وسائل الاعلام. r-درجة اسهام وسائل الإعلام في ترسيخ القيم التربوية لدى الطفل العراقي.

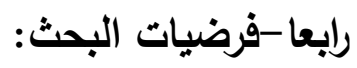
1-لا توجد فروق ذات دلالة إحصائية بمدى اسـهام الصحف والمجلات في ترسيخ القيم التزبوية لدى الطفل العراقي تبعا لمتغير الجنس؟

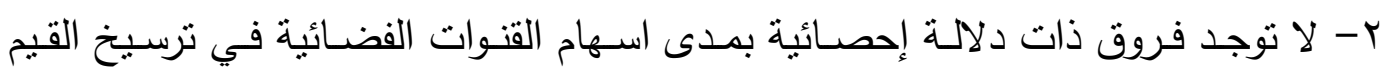

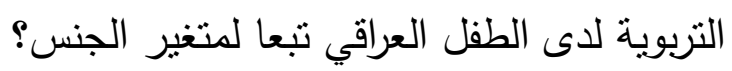

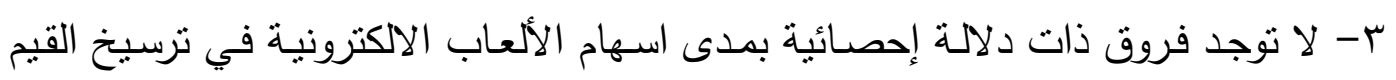

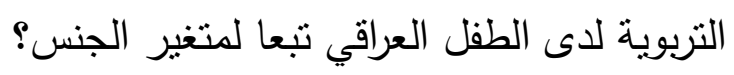

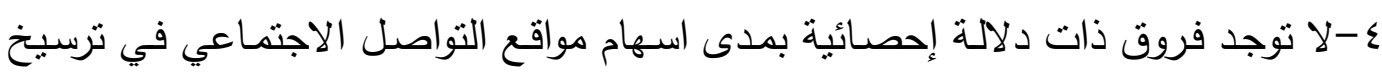
القيم التربوية لدى الطفل العراقي تبعا لمتغير الجنس؟ دوفي داته 0- لا نوجد فروق ذات دلالة إحصائية بمدى اسهام عمليات البحث في ترسيخ القئيم التربوية

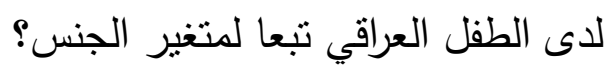
خامسا-منهج البحث ونوعه: تم الاعتماد في مجال بحثنا على المنهج المسحي والذي يهدف إلى مسح آراء الأطفال،

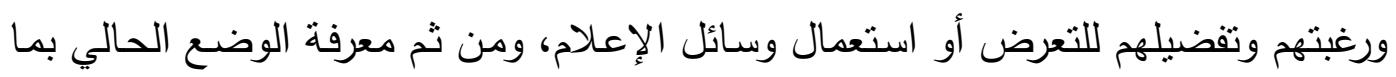

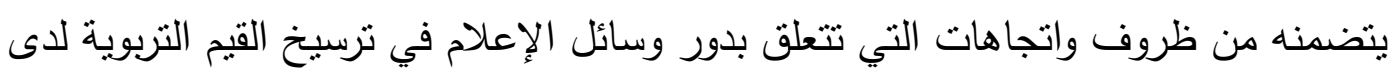
الطفل. 
ا-المجال الموضوعي: والمتمثلة بدراسة وسائل الإعلام والقيم التربوية (الصحف والمجلات، القنوات الفضائية، الألعاب الالكترونية، مواقع التواصل الاجتماعي، عمليات البحث).

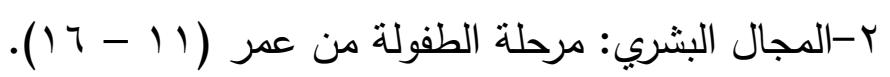
r-المجال المكاني: المدارس الابتدائية والمنتوسطة والرابع الاعدادي في في محافظات (بغداد والمثنى وصلاح الدين).

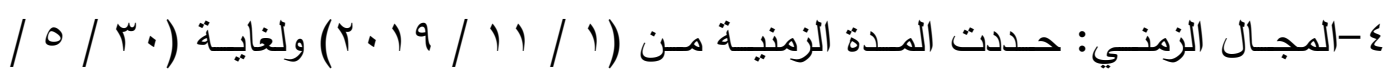

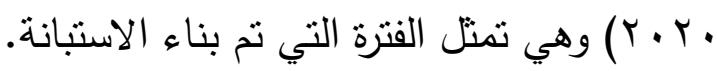

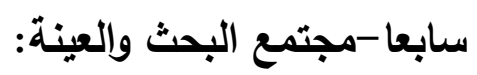
تكون مجتمع البحث من شريحة الأطفال ممن تبلغ أعمارهم من (1) (1 - 17 (1) سنة،

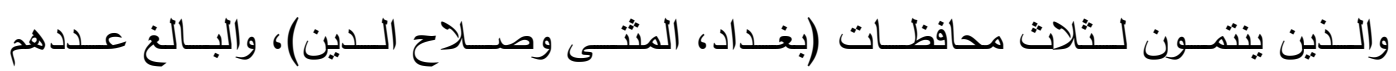

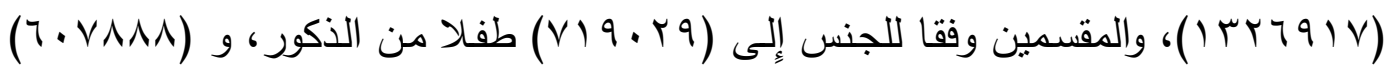
طفلا من الاناث. كما وتم سحب عينة البحث بالطريقة العشوائية من ثلاث محافظات والتي

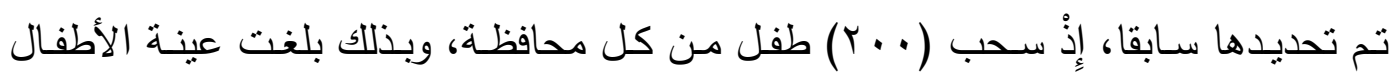

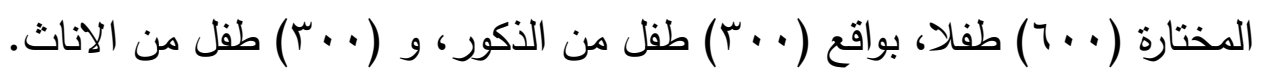
ثامنا-أدوات البحث: 1-المقابلة: وهي مجموعة من الأسئلة المفتوحة التي قامت الباحثة بعرضها على مجموعة

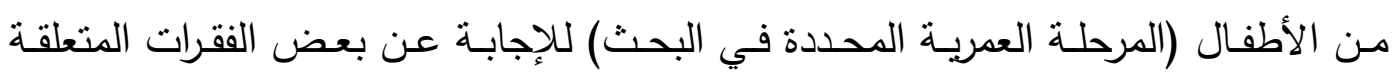
بموضوع البحث، ولقد استفاد الباحثان منها في بناء استبانة البحث.

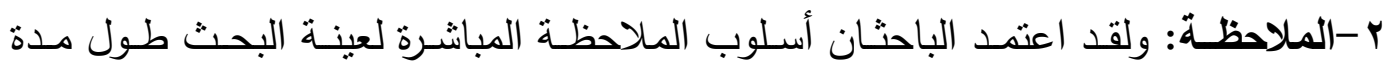
تطبيقها لاستبانة البحث، وهو ما سنح لها الفرصة للحصول على معلومات إضـافية حول موضوع بحثها. r-استمارة الاستبانة: ويقصد بها تلك الأداة التي تستعمل للحصول على جميع البيانات

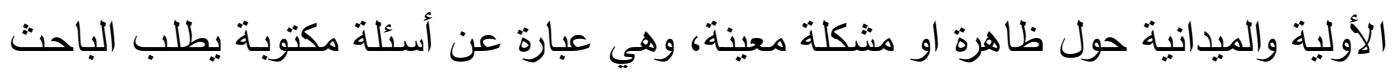

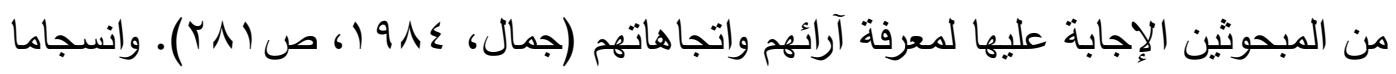

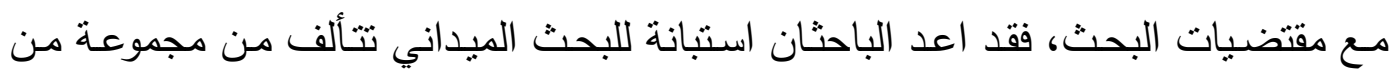
البنود للكثف عن مستوى دور وسائل الإعلام في ترسيخ القيم التربوية لدى الطفل العراقي. تاسعا-إجراءات الصدق والثبات: 1-الصدق: يعد الصدق من الخصائص التي ينبغي نوافرها في أدوات جمع البيانات، أي واتي

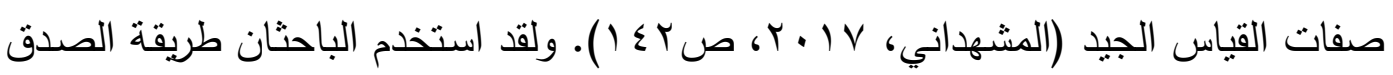




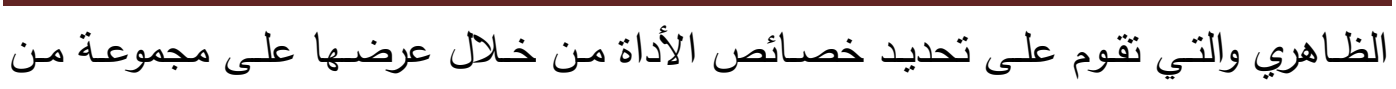

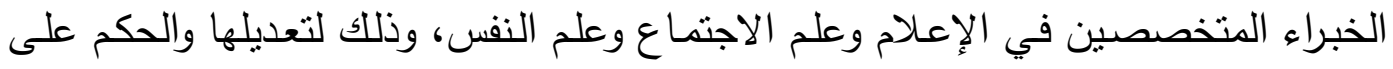

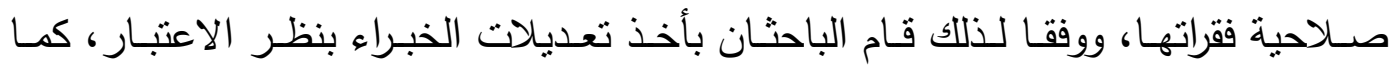
وتوصلا إلى استخراج صدق الظاهري لاستبانة البحث بعد ان حصلت على نسبة إندان اتفاق بين

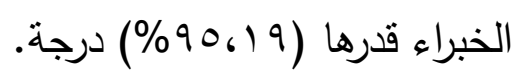

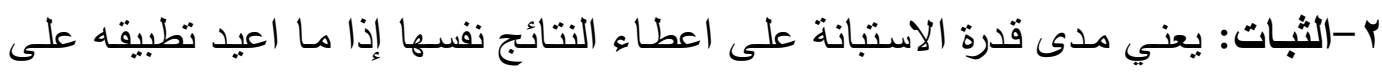

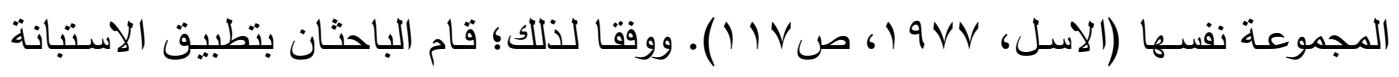

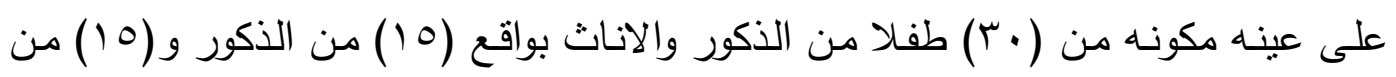

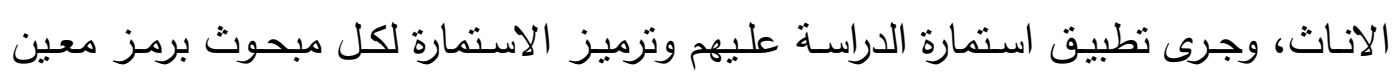

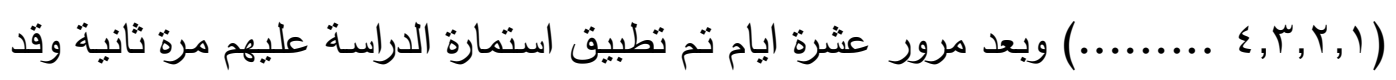

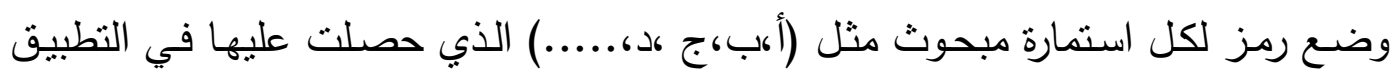

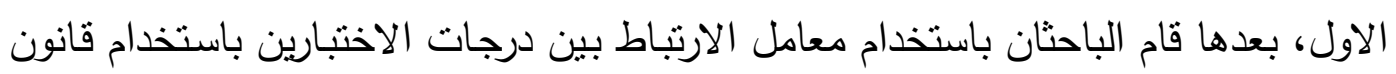

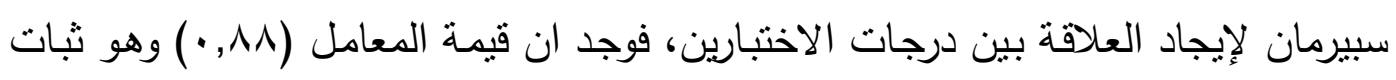

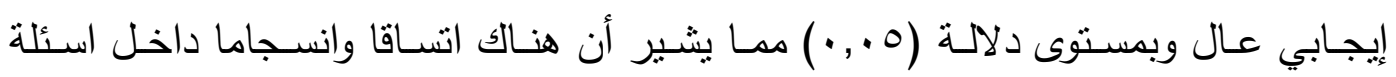

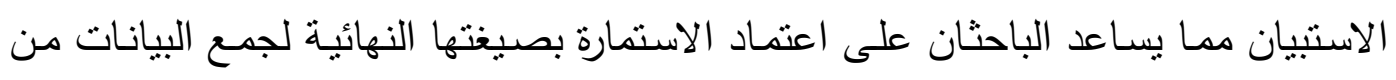

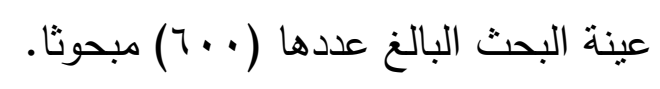
عاشرا-الادراسات السابقة:

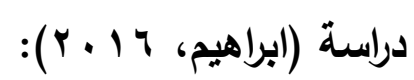

هدفت معرفة دور الصحافة في غرس قيم النزاهـة لدى الأطفال، والدور الذي تلعبـه

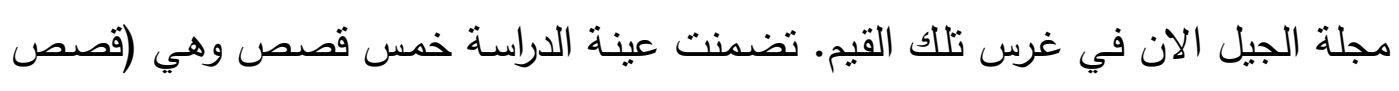
المثل العليا والنزاهة، القصص الواقعية، القصص الخيالية، قصص البطولة وقصص لإنداء

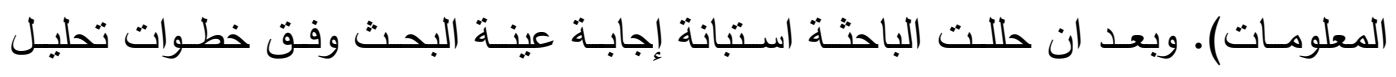

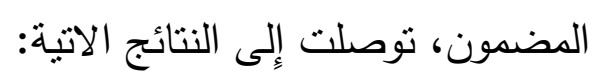

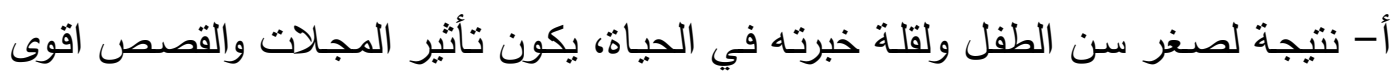

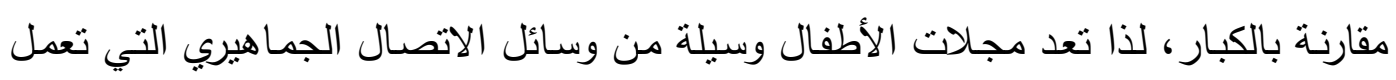
على تثقيف الأطفال وتزويدهم بالخبرات والقيم الحميدة.

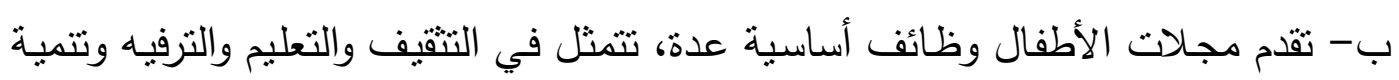
التتشئة الاجتماعية الصالحة. 
ج- تتمية المهارات اللغوية للطفل، إذْ تساعد المجلات على تحفيز الطفل لكتابة قصص من

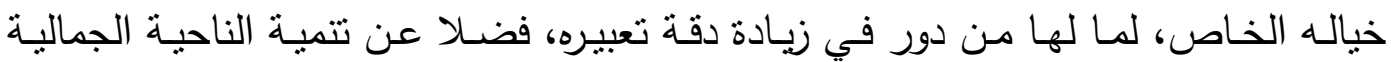

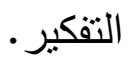

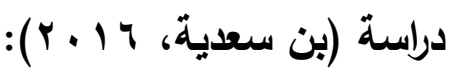

هدفت معرفة مضمون القيم الدينية في برامج القناة التلفزيونية للأطفال. وقد نألفت عينـة

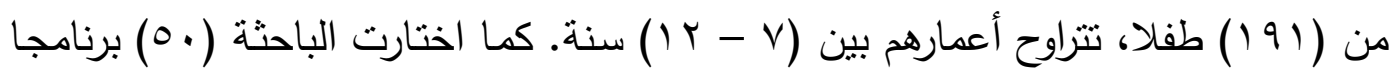

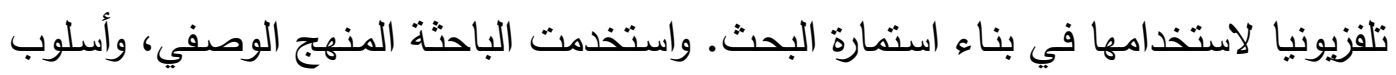

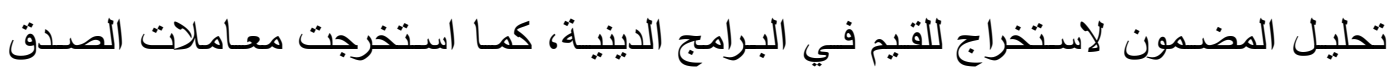
والثبات لأداة تحليل المضدون. وبعد ان حلت الباحثة استبانة إجابـة عينة البحث وفق خطوات تحليل المضمون،

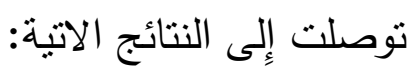
أ- أن القيم الدينية الإسلامية لم تشكل قاعدة أساسية في صياغة محتوى برنامج "نون" كما أنَّهُ لا يركز على القيم العقائدية بقدر تركيزه على القيم الفنية بهدف تطوير موهبة البنات، وكذا القيم الثخصية والقيم الصحية.

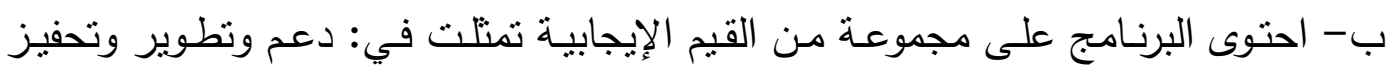

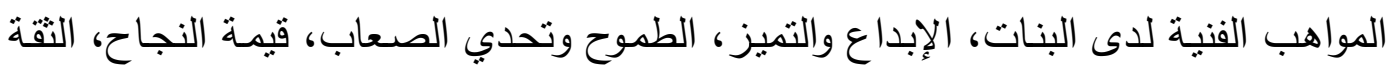

$$
\begin{aligned}
& \text { بالنفس (بن سعدية، } 77 \text { ـ ب). }
\end{aligned}
$$

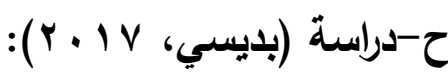

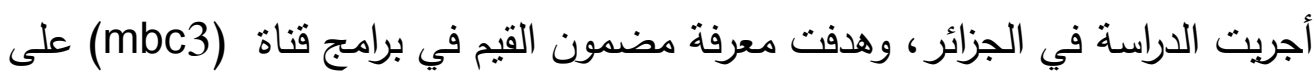

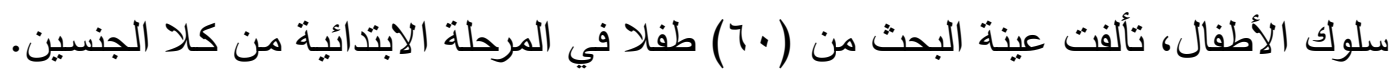
واستخدمت الباحثة المنهج الوصفي، وأسلوب تحليل المضمون للقيم في برامج قناة (mbc3)

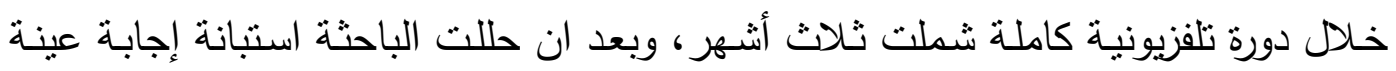
البحث وفق خطوات تحليل المضدون، توصلت إلى النتائج الاتية: أ- تنوعت البرامج التي تم عرضهها في برامج قناة (mbc3) من بين أفلام ومسلسـلات

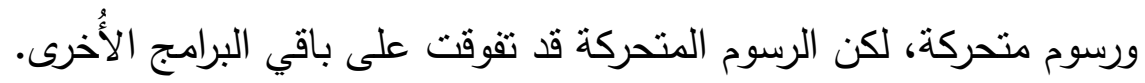

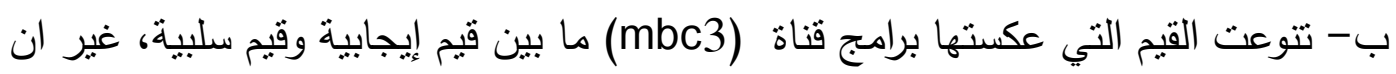

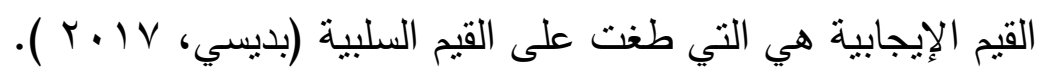

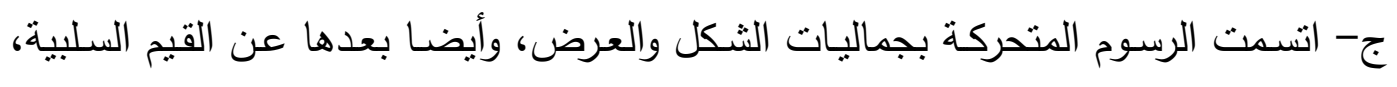

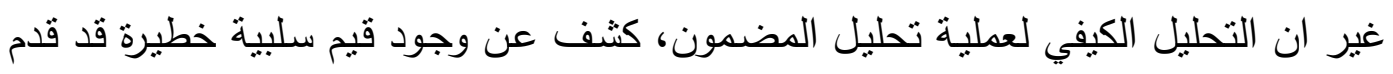
بشكل ضمني مع القيم الإيجابية، ولاسيما ما يخص منها بالجانب العقائدي. 
تعد القيم التزبوية نتاج الثقافة المتولدة من الأفراد والجماعات، وهي من اهم العوامل التي من خلالها بحكمون وجودهم الاجتماعي، ويحافظون بها على أوضاعهم الاجتماعية،

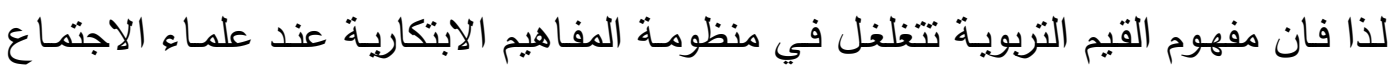

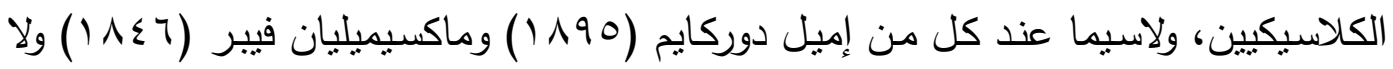
غرور في ذلك لان الوحدة الاجتماعية تقوم على أساس وحدة القيم الكامنة في وعي الأفراد،

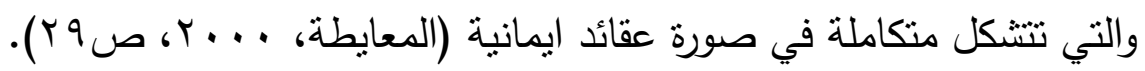

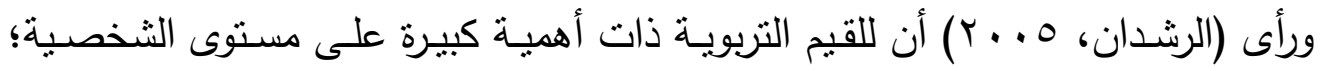

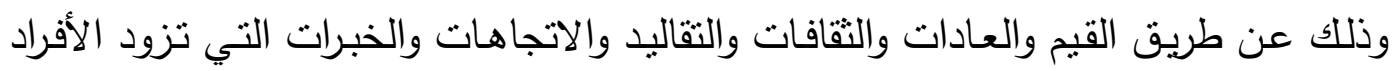

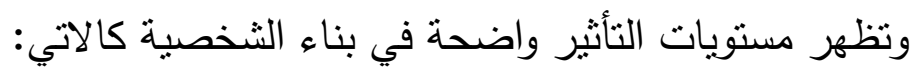
1- المحتوى: وهي مجموعة من الأنماط السلوكية الإيجابية الواقعية التي ينقلها الجيل السابق بشكل مباشر إلى الجيل اللاحق. ب- التفسير : فالأفراد في أي مجتمع يقومون بنقل التقافة إلى الأطفال بطرق مختلفة، والتي من خلالها يتم ترسيخ السلوكيات السليمة.

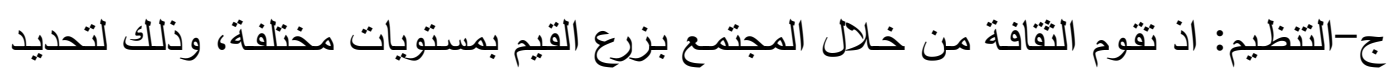

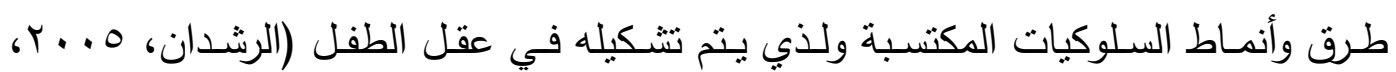

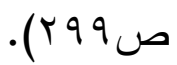
ثانيا: وسائل الإعلام في التنشئة الاجتماعية للطقل:

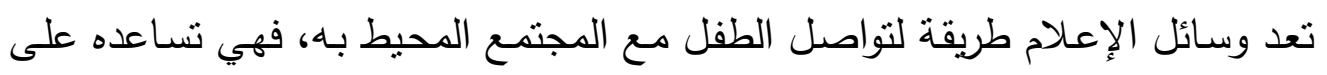

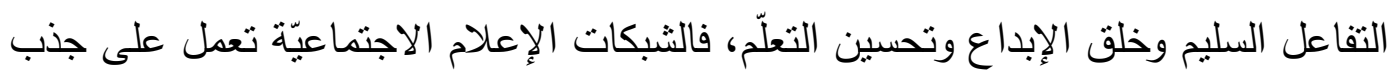

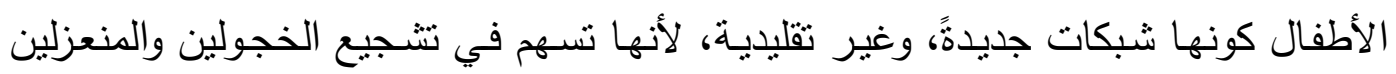

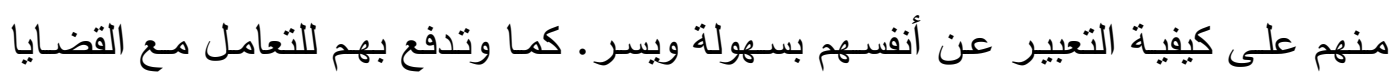

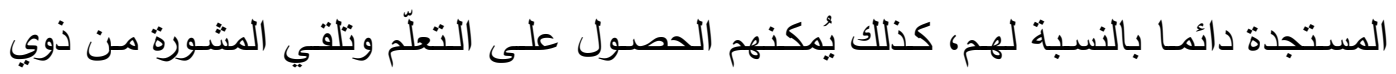

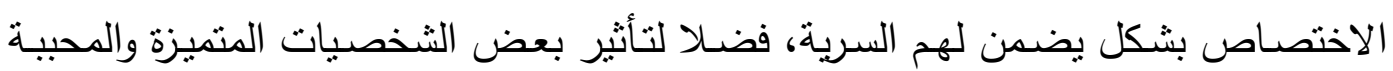

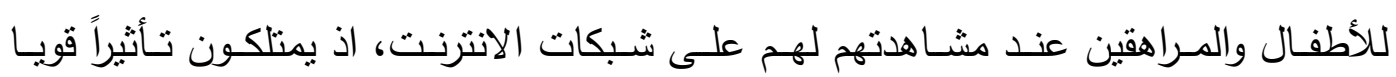

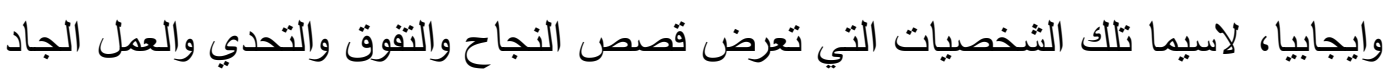

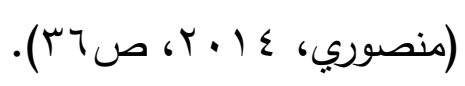

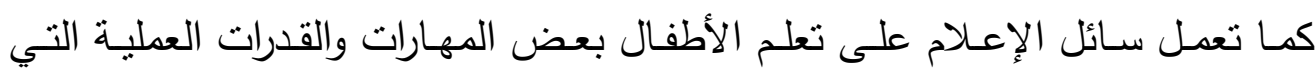
أصبحت من الحاجات الضرورية لمواجهة القضايا والتحديات العصرية، اذ يتعلم الأطفال 
كيفية استخدامهم للتقنيات المتطورة والحديثة بمهارة وكفاءة، وهذا ما يعزز قدراتهم الابتكارية

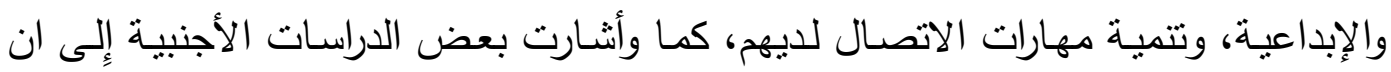

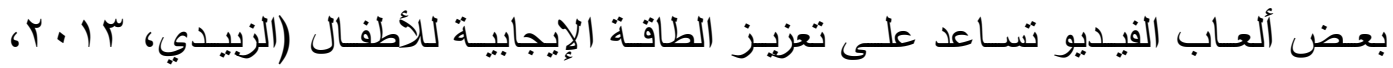

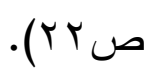
ثالثا-النظرية المعتمدة في البحث:

نظرية الاعتماد على وسائل الإعلام (Media system dependency theory)

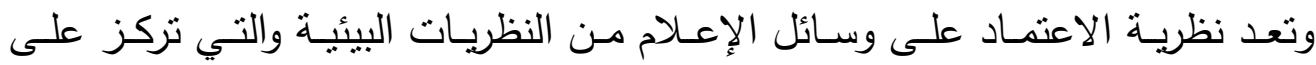

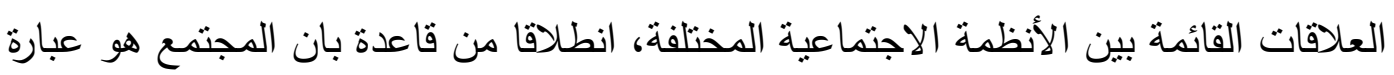

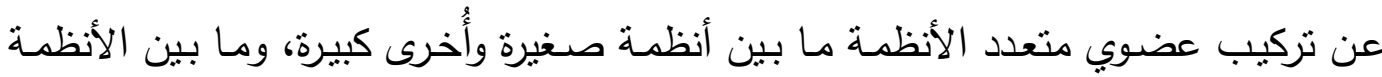
الذكرية والأُخرى الانثوية، فضلا عن دراسة مدى تفاعل وترابط العلاقات المتبادلة فيما بين الانئ

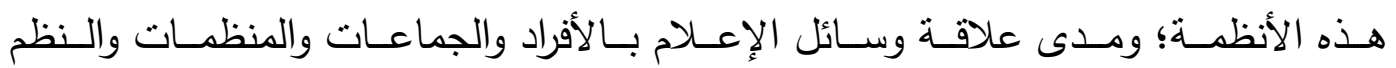

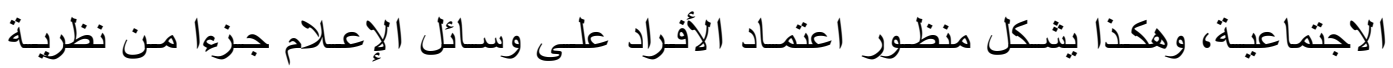

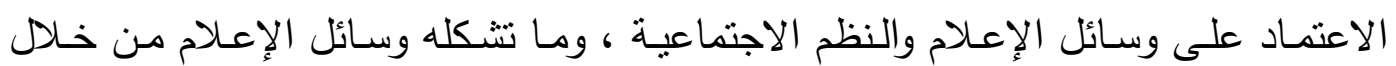

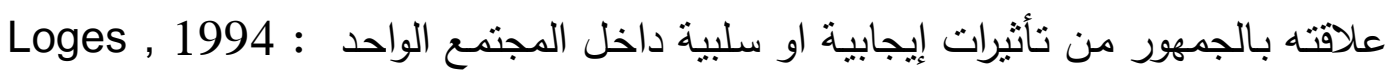

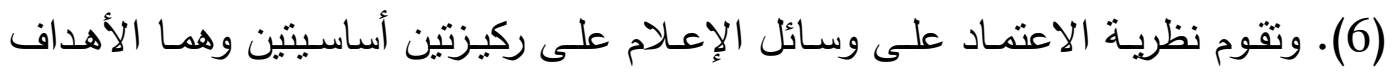

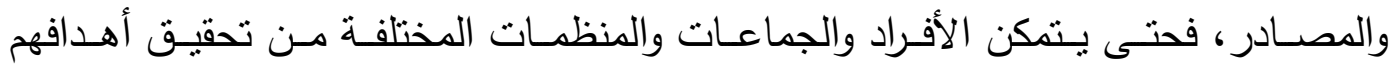

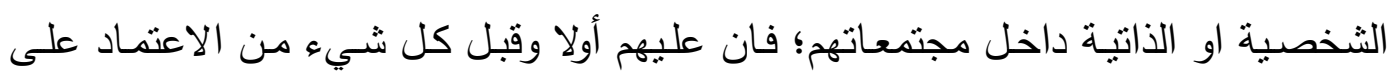

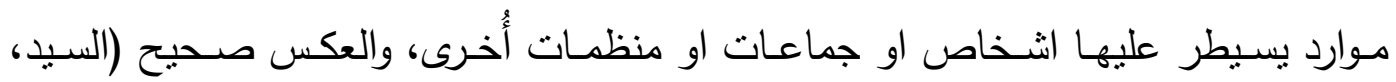

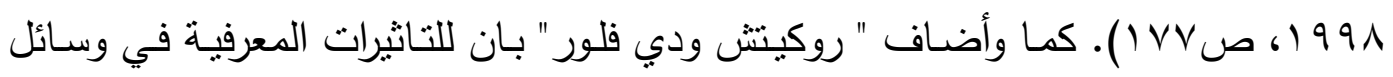

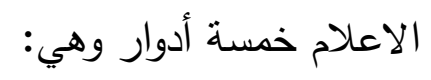
اولا- الغموض: وتحدث عندما يواجها الفرد حالـة مـن نقص المعلومـات المتاحـة لدى الجمهور، مما يدفعه للجوء لوسائل الإعلام المختلفة من اجل البحث عن المعلومات لتذليل

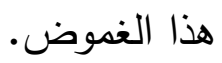
ثانيا- تكوين الاتجاهات: وهنا تقوم وسائل الإعلام بدور تشكيل الاتجاهات لدى الأفراد، لاسيما تجاه القضايا السياسية والاجتماعية. ثالثا- ترتيب الأولويات: بمعنى ما لوسائل الإعلام من دور في ترتيب اهتمامات الأفراد

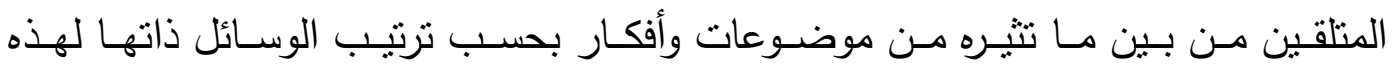

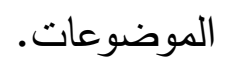
رابعا- اتساع المعتقدات: وذلك بتأثثر وسائل الإعلام على نظم معتقدات واراء واتجاهات

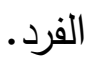


خامسا- القيم :اذ تعمل وسائل الإعلام على ترسيخ القيم والمبادئ التربوية والتي يشترك فيها أفراد جماعة معينة فيها، والذين يرغبون في ترويجها والحفاظ عليها في مجتمعاتهر من خلال زرعها وترسيخها بوسـائل مختلفة، ومـن امتلتها قيم التسـامح، والحريـة، والعدل والمسـاواة، والتعاون والمساعدة، والايمان، وحب الوطن، اذ يكون لوسائل الإعلام دور كبير في توضيح

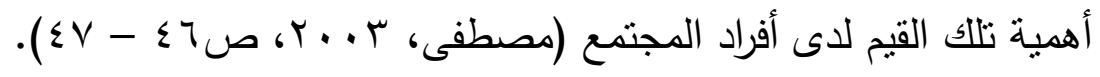
عرض وتحليل بيانات الدراسة

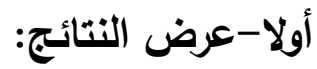

ولقد تم استعراض النتائج التي توصلت إليها المعطيات الميدانيـة للاراسـة على وفق

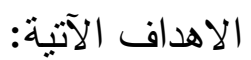

أولا-نوع القيم التربوية السائدة لدى الطفل العراقى في ضوء دور وسائل الاعلام.

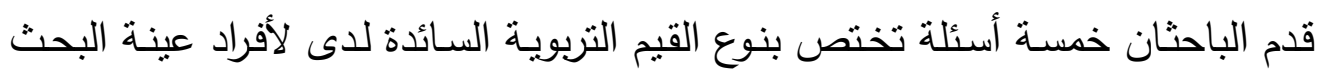

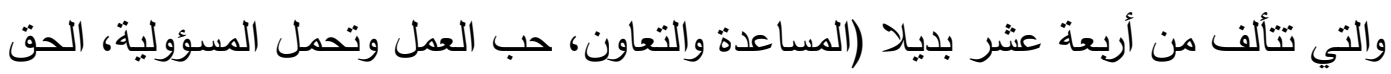

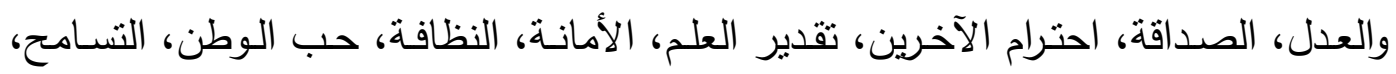

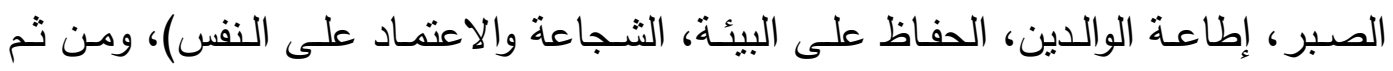

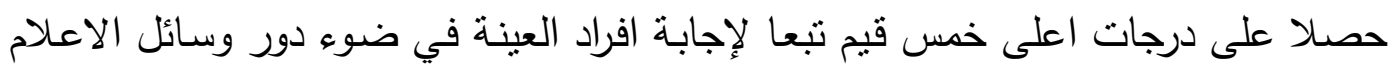

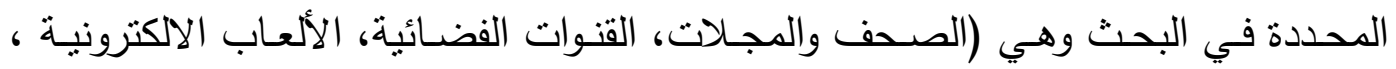

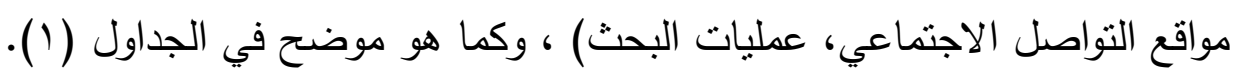

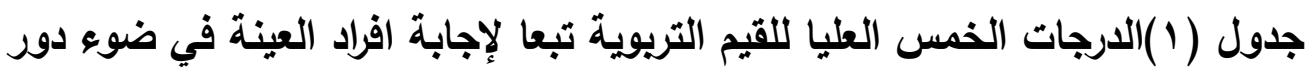

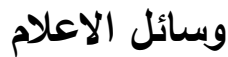

\begin{tabular}{|c|c|c|c|c|c|c|}
\hline \multicolumn{5}{|c|}{ وسائل الاعلام } & \multirow[b]{2}{*}{ القيم التريوية } & \multirow[b]{2}{*}{$\Xi$} \\
\hline البحث & الاجتماصل مواقع & الاكترونية & الفضائية & والمجلات & & \\
\hline$\% 9$ & $\% \curlyvee$ & $\% 9$ & $\% 1$ & $\%$ iv & المساعدة والتعاون & -1 \\
\hline$\% q$ & $\% ч$ & - & $\%$ ! & $\%$ וr & حب العمل وتحمل المسؤولية & $-r$ \\
\hline - & - & - & - & _ & الحق والعدل & $-r$ \\
\hline$\% \wedge$ & $\% \wedge$ & $\% 19$ & - & _ & الصداقة & צ \\
\hline$\% q$ & $\% q$ & $\%$ १६ & $\% 1 r$ & $\% 17$ & احترام الاخرين & -0 \\
\hline$\% 1$. & $\% 1$. & - & - & $\% 11$ & تقدير العلم & -9 \\
\hline$\% \wedge$ & $\% \wedge$ & - & $\% \wedge$ & _ & الامانة & $-v$ \\
\hline
\end{tabular}




\begin{tabular}{|c|c|c|c|c|c|c|}
\hline- & $\% 4$ & - & - & - & النظافة & $-\Lambda$ \\
\hline$\%$ & $\% \wedge$ & - & - & - & حب الوطن & -9 \\
\hline$\% 4$ & $\%$ & - & $\% 11$ & - & التسامح & -1 . \\
\hline$\% \vee$ & $\% \mathrm{~V}$ & $\% 17$ & - & - & الصبر & -11 \\
\hline- & - & - & - & - & اطاعة الوالدين & $-1 r$ \\
\hline$\%$ & $\% 9$ & - & - & $\% 1$. & الحفاظ على البيئة & $-1 \mu$ \\
\hline$\% 1$. & $\% \wedge$ & $\% \backslash \wedge$ & $\% \wedge$ & - & الشجاعة والاعتماد على & $-1 \leqslant$ \\
\hline
\end{tabular}

من خلال ملاحظة البيانات الواردة في الجدول أعلاه نلاحظ ان إجابة عينة البحث فيما يتعلق بدور الصحف والمجلات في ترسيخ القيم التربوية ، بان البديل (المساعدة والتعاون)

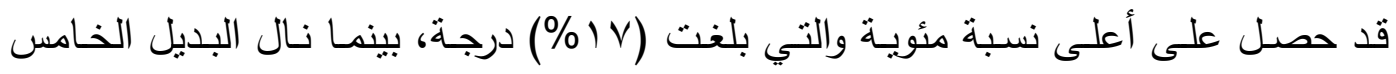

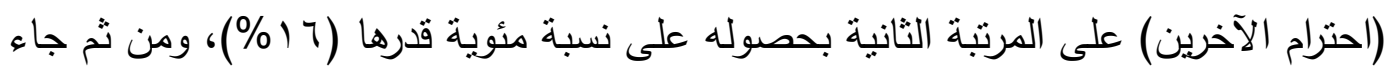
البديل الثاني (حب العمل وتحمل المسؤولية) على المرتبة الثالثة، وذللك عند نيله على نسبة لئه مئوية قدرها (r (1\%)، كما وجاء البديل السادس (تقدير العلم) لينال المرتبة الرابعة بحصوله

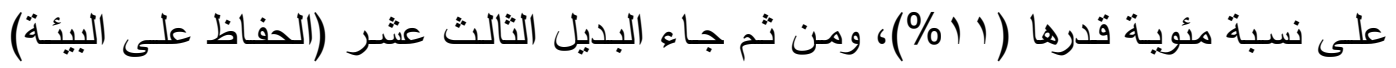

$$
\text { ليحصل على المرتبة الخامسة بنيله نسبة مئوية قدرها (• (1\%). }
$$

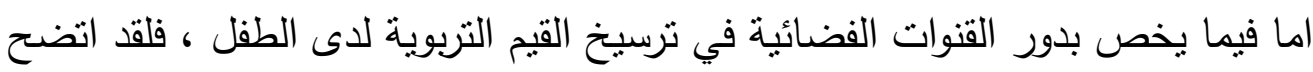

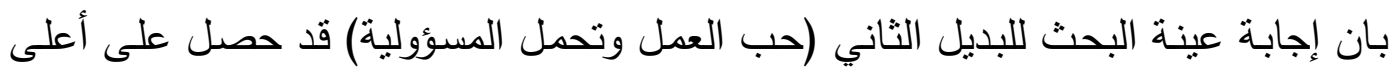

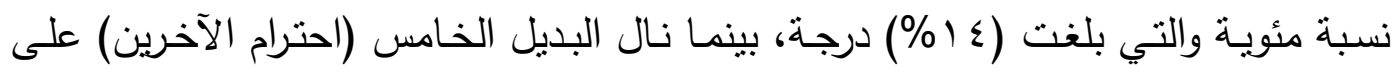

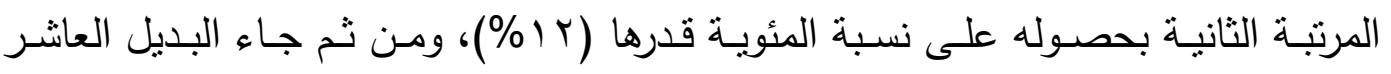

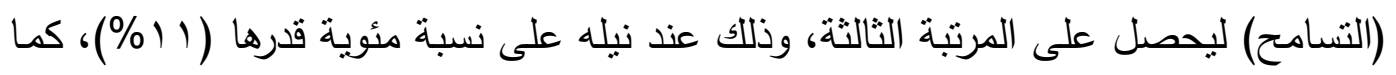
وجاء البديل الأوَّل (المساعدة والتعاون) لينال المرتبة الرابعة بحصوله على نسبة مئوية قدرها

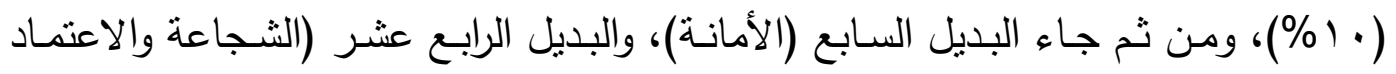

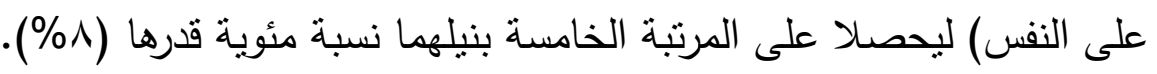

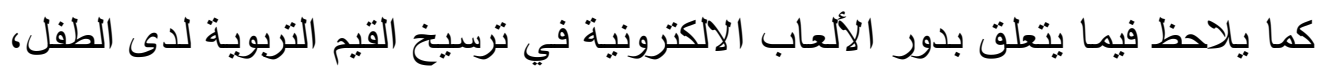

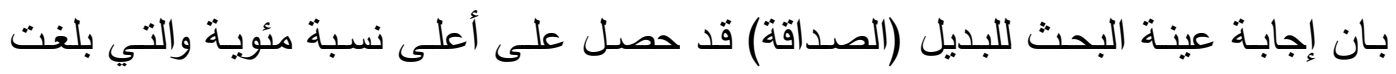
(9 \% (19) درجة، بينما نال البديل الرابع عشر (الثجاعة والاعتماد على النفس) على المرنبة

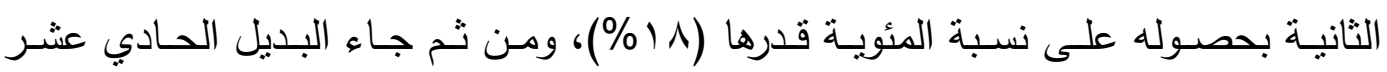

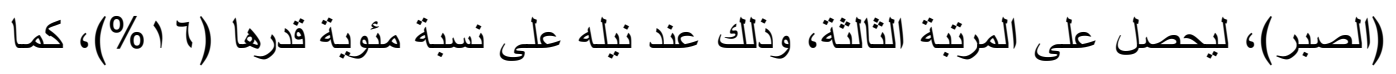
وجاء البديل الخامس (احترام الآخرين) لينال المرتبة الرابعة بحصوله على على نسبة مئوية قدرها 
(ع ا \%)، كما وحصل البديل الأوَّل (المساعدة والتعاون) على المرتبة الخامسة، بنيله نسبة

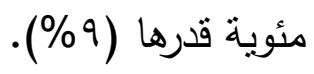

ولقد أظهرت نتائج دور مواقع التواصل الاجتماعي في ترسيخ القيم التربوية لدى الطفل،

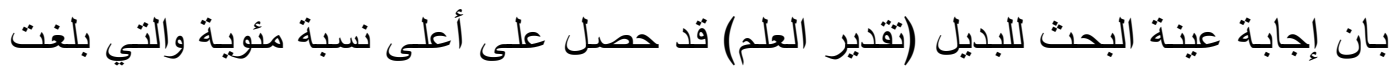

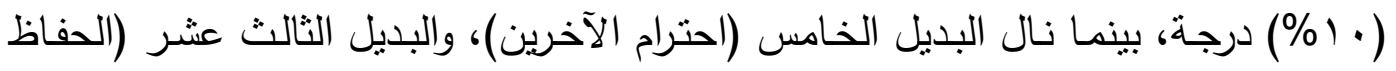

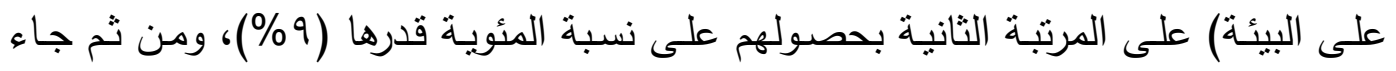

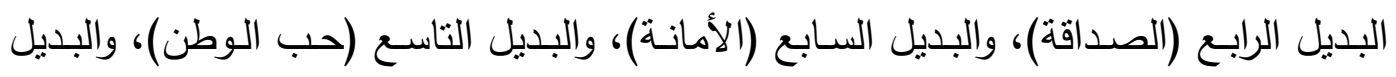

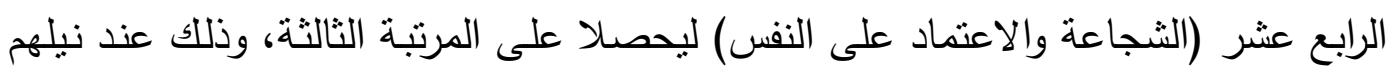

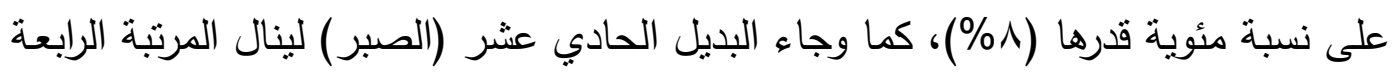

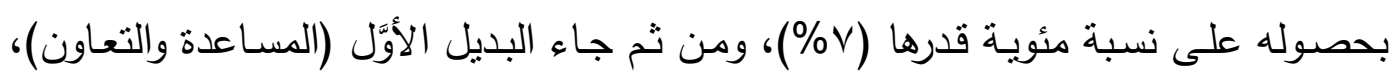

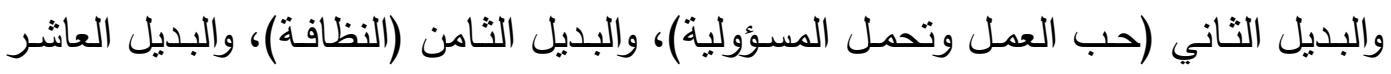

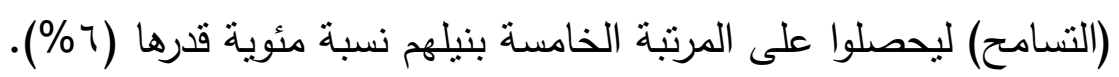

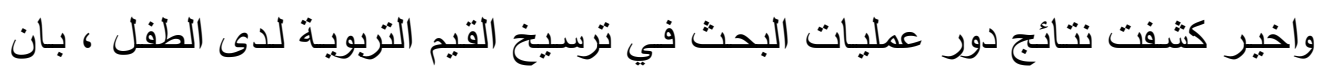
إجابة عينة البحث للبديل السادس (تقدير العلم)، والبديل الرابع عشر (الثجاعة واتئ والاعتماد

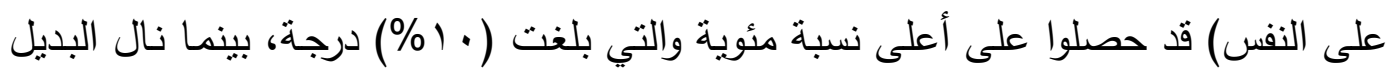

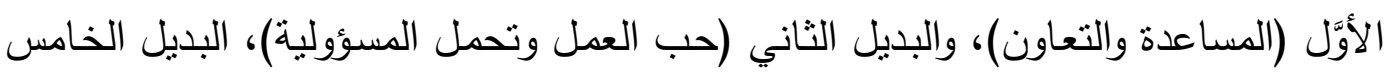

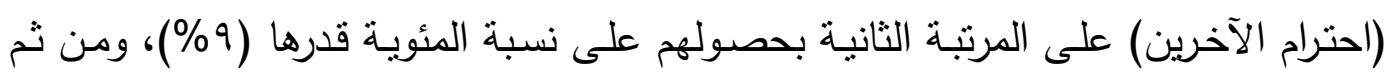

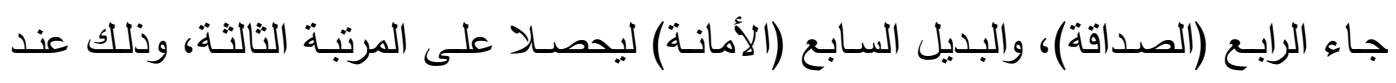

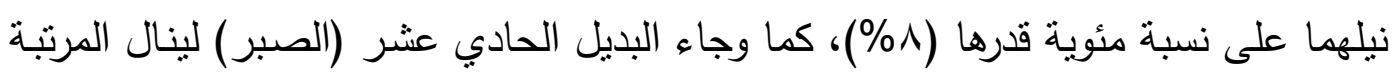

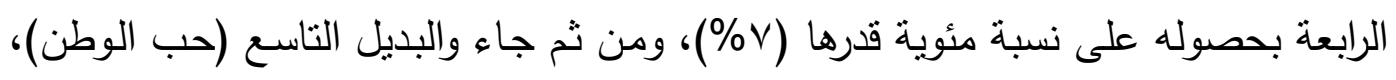

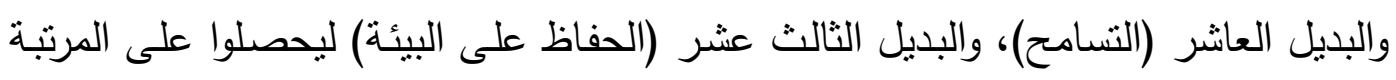
الخامسة بنيلهم نسبة مئوية قدرها (T\%).

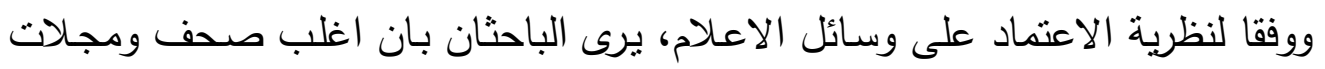

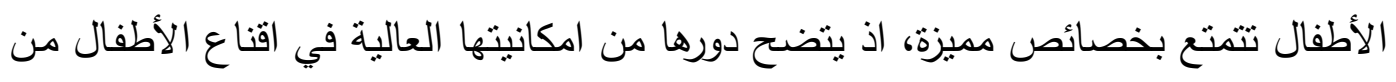

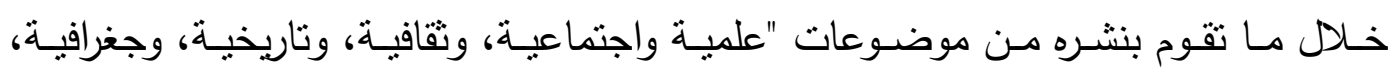
ورياضية ..." وغيرها من الموضوعات المختلفة على التمسك بالقيم التربوية السليمة. فضلاعلا

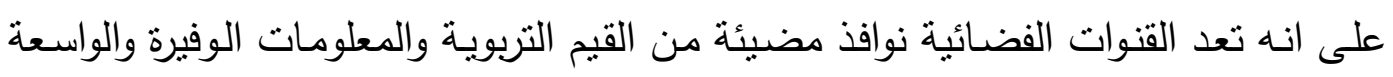

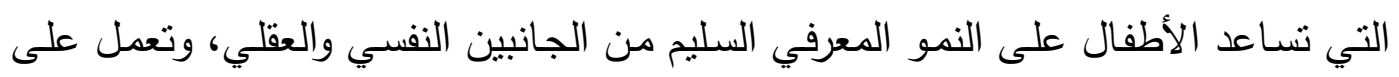
إثباع حاجاته من المعلومات ومن ثم تهيئته للدخول المدرسة والحياة. 
ويضيف الباحثان بان للألعاب الالكترونية دورا مهما في اكتساب الأطفال مجموعة من القيم التزبوية، والتي تشعرهم بالثقة بالنفس، وتزيد من ارتفاع بتقدير واحترام الذات، والثعور

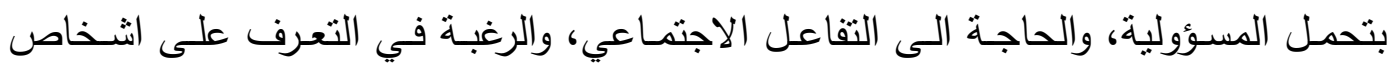
اخرين، وحب الصداقة، والمشاركة الاجتماعية. كما تشكل مواقع التواصل الاجتماعي دورا

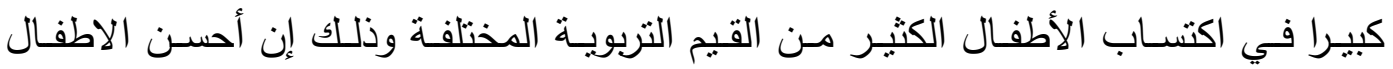

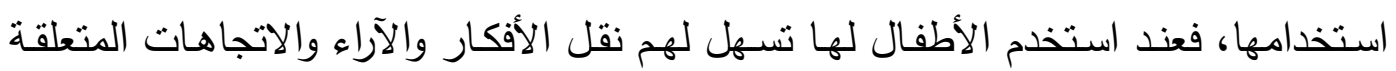

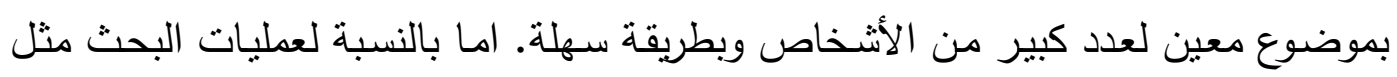

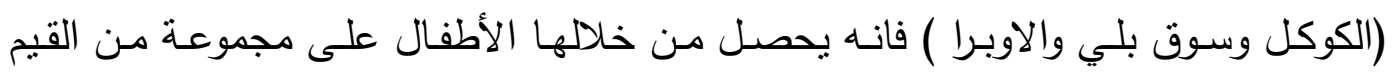

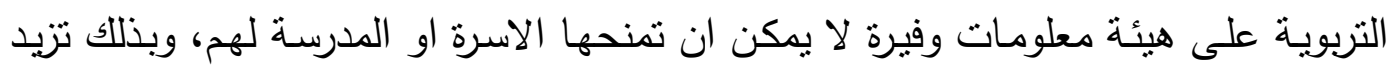

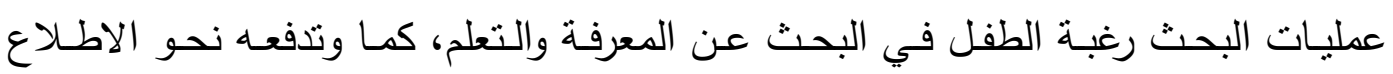
والاستطلاع العلمي الدقيق. ץ-درجة اسهام وسائل الإعلام في ترسيخ القيم التربوية لادى الطفل العراقي.

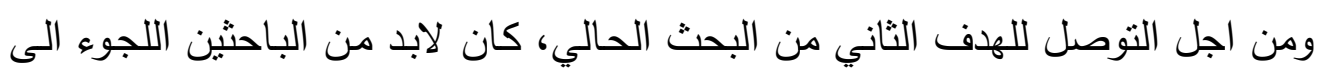

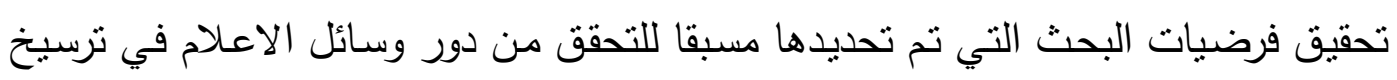
القيم التربوية لدى الطفل العراقي، وفيما يلي عرضا لهذه الفرضيات:

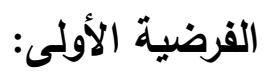
1-لا توجد فروق ذات دلالة إحصائية بمدى اسـهام الصحف والمجلات في ترسيخ القيم

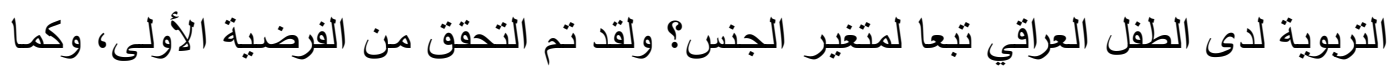

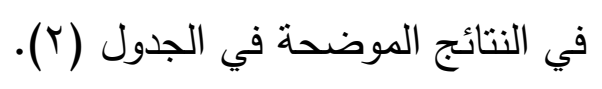

الجدول (Y) مدى إسهام الصحف والمجلات في ترسيخ القيم التريوية لدى الطفل العراقي (Y)

تبعا لمتغير الجنس

\begin{tabular}{|c|c|c|c|c|c|c|}
\hline \multirow{2}{*}{ مستوى الدلالة } & \multicolumn{2}{|c|}{ قيمة مريع كاي r } & \multirow{2}{*}{ القيم التريوية } & \multicolumn{2}{|c|}{ الجنس } & \multirow{2}{*}{ المجموع } \\
\hline & |الجدولية & المحسوية & & إناث & ذكور & \\
\hline \multirow{5}{*}{ غير دال عند } & \multirow{5}{*}{ YYGTY } & \multirow{5}{*}{$1 \leq 6 V Y q$} & المساعدة والتعاون & $r$. & 9 & rq \\
\hline & & & حب العمل وتحمل & 18 & 11 & YV \\
\hline & & & الحق والعدل & $r$ & . & $r$ \\
\hline & & & الصداقة & $r$ & $\varepsilon$ & 1 \\
\hline & & & احترام الآخرين & rl & $1 \leq$ & ro \\
\hline
\end{tabular}




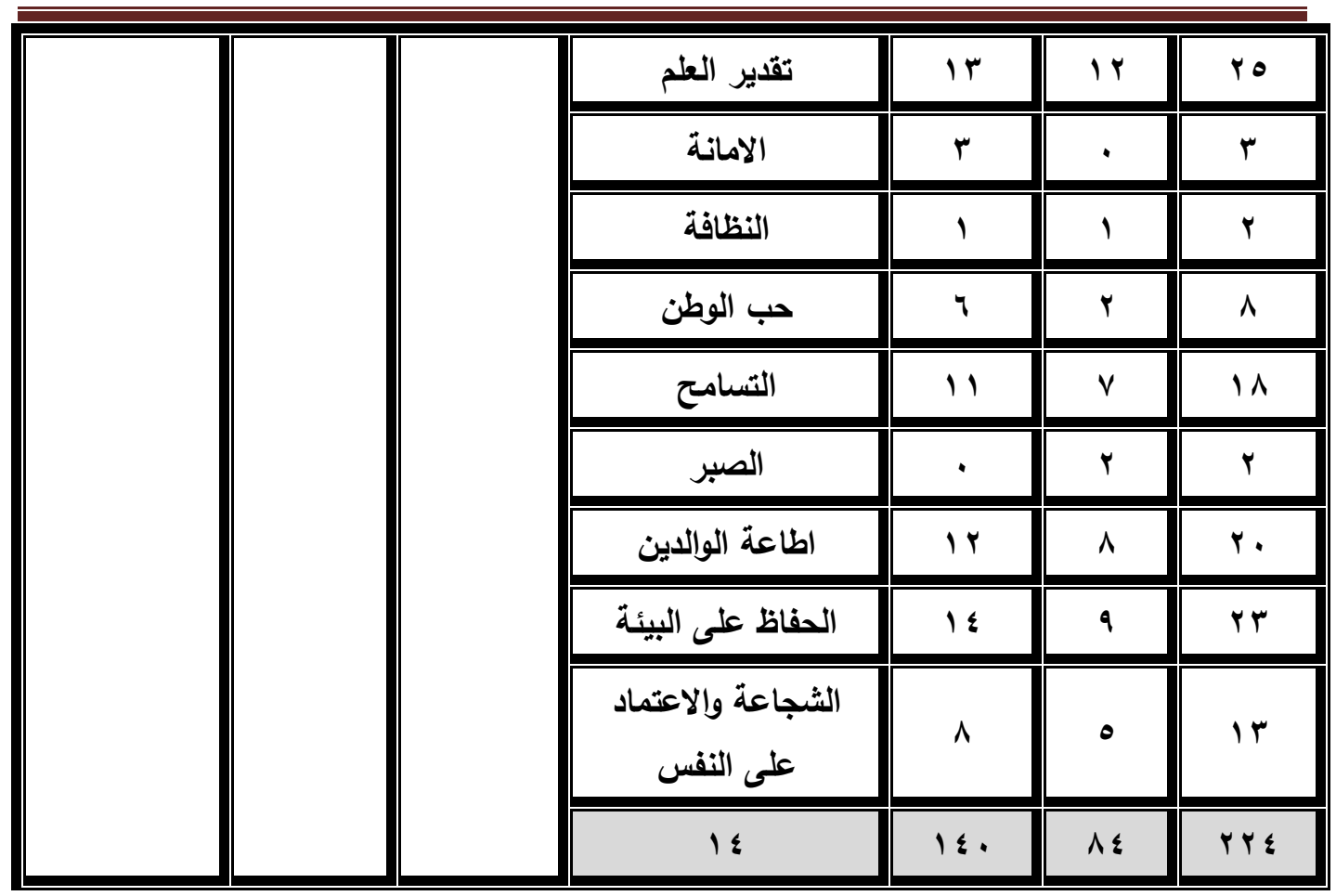

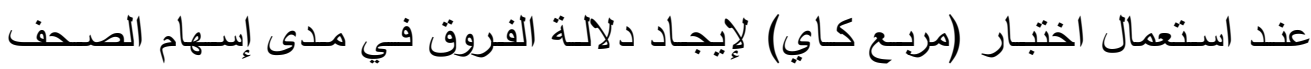

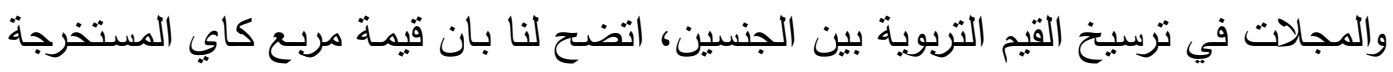

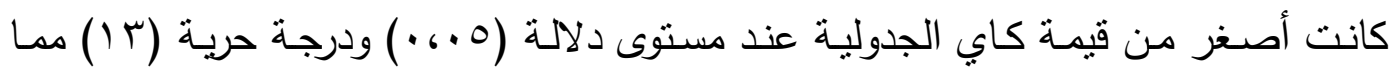

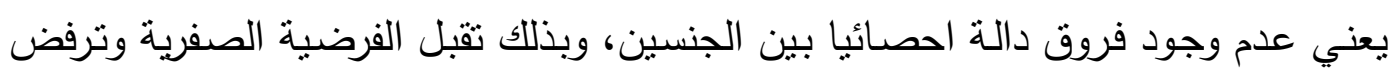
البديلة. ويمكن تفسير النتيجة الحالية على وفق نظرية (الاعتماد على وسائل الإعلام) بان

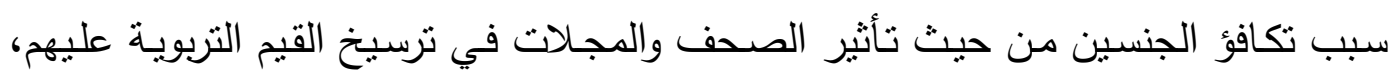

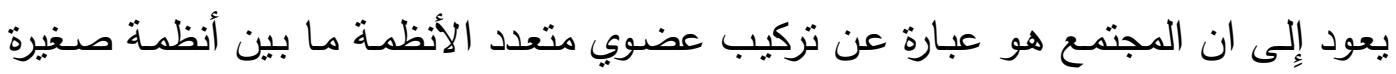

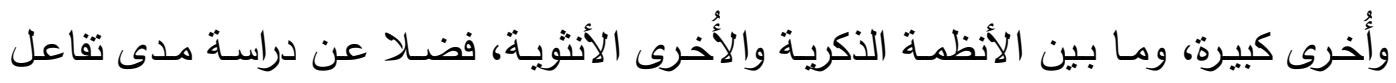

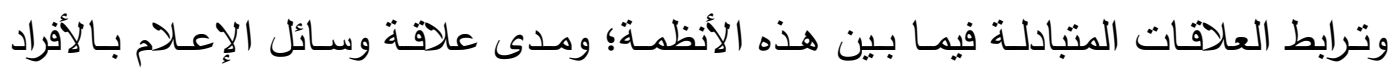

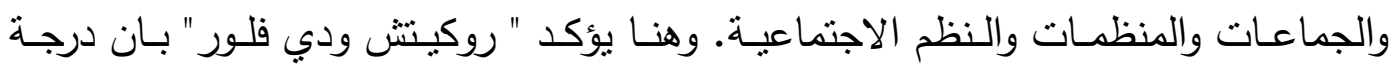

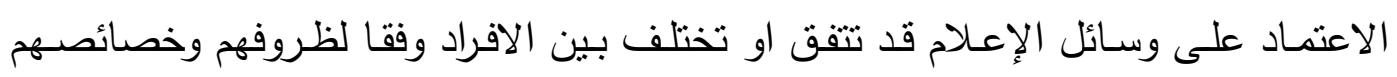

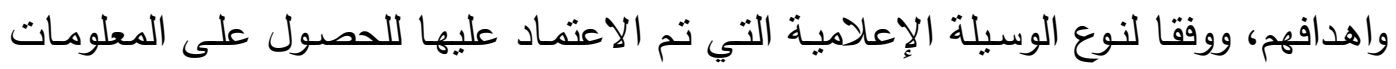
التي يرغبون بها. الفرضية الثانية: - التية r- لا توجد فروق ذات دلالـة إحصـائية بمدى اسهام القنوات الفضـائية في ترسيخ القيم التربوية لاى الطفل العراقي تبعا لمتغير الجنس؟ ولقد نم التحقق من الفرضية الثانية، وكما في النتائج الموضحة في الجدول (r). 


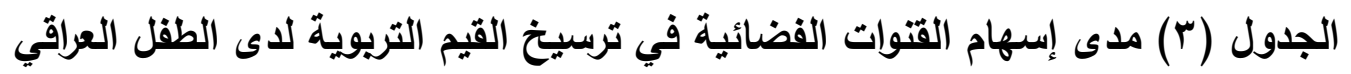

تبعا لمتغير الجنس

\begin{tabular}{|c|c|c|c|c|c|c|}
\hline \multirow{2}{*}{ مستوى } & \multicolumn{2}{|c|}{ قيمة مريع كاي r } & \multirow{2}{*}{ القيم التريوية } & \multicolumn{2}{|c|}{ الجنس } & \multirow{2}{*}{ المجموع } \\
\hline & الجدولية & المحسوية & & إناث & ذكور & \\
\hline \multirow{15}{*}{ مستوى دلالة } & \multirow{15}{*}{ TrGTY } & \multirow{15}{*}{ TVGVIT } & المساعدة والتعاون & ir & rr & rT \\
\hline & & & حب العمل وتحمل & IV & $r r$ & 0. \\
\hline & & & الحق والعدل & 7 & 0 & 11 \\
\hline & & & الصداقة & 7 & 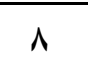 & $1 \varepsilon$ \\
\hline & & & احترام الآخرين & 10 & $r$. & $\leq 0$ \\
\hline & & & تقاير الطلم & $r$ & 11 & ri \\
\hline & & & الامانة & $\Lambda$ & $r$. & $r \wedge$ \\
\hline & & & النظافة & 7 & 7 & ir \\
\hline & & & حب الوطن & ir & $\wedge$ & $r$. \\
\hline & & & التسامح & 0 & ro & $\varepsilon$ \\
\hline & & & الصبر & 9 & 1. & 19 \\
\hline & & & اطاعة الوالدين & $1 \leq$ & 7 & r. \\
\hline & & & الحفاظ على البيئة & 14 & $r$ & 17 \\
\hline & & & الثجاعة والاعتماد على & ro & 0 & r. \\
\hline & & & $1 \varepsilon$ & lor & ri. & rit \\
\hline
\end{tabular}

عند استعمال اختبار (مربع كاي) لإيجاد دلالة الفروق في مدى إسهام القنوات الفضائية

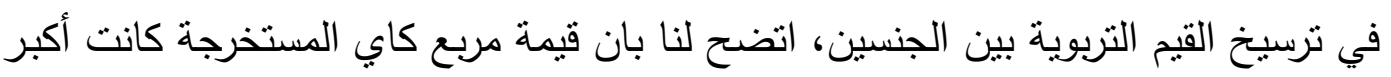

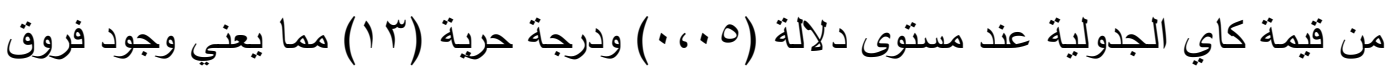
دالة احصائيا بين الجنسين ولصالح الذكور ، وبذللك ترفض الفرضية الصفرية وتقبل البديلة. ويمكن تفسير النتيجة الحالية على وفق نظرية (الاعتماد على وسائل الإعلام) بان سبب لإنبان

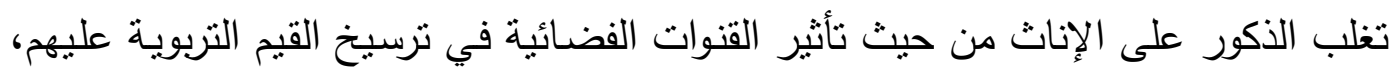

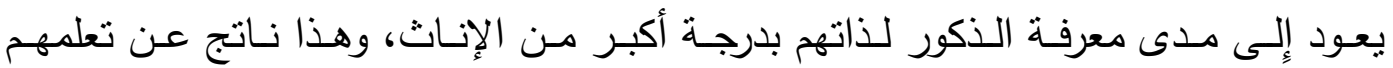


وحصولهم على خبرات أوسع عن طريق الاحتكاك المباشر بالنظام الاجتماعي المتواجدين فيه، فضلا عن فهمه للبيئة الاجتماعية المحيطة بهم مع محاولة تفسيرها.

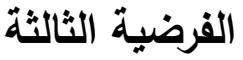
r- لا توجد فروق ذات دلالة إحصائية بمدى اسهام الألعاب الالكترونية في ترسيخ القيم

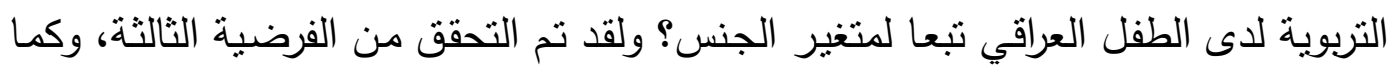

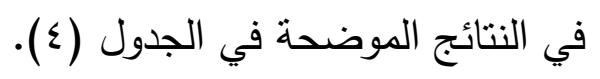

الجدول (؛ ) مدى إسهام الألعاب الالكترونية في ترسيخ القيم التربوية لاى الطقل العراقي

$$
\text { تبعا لمتغير الجنس }
$$

\begin{tabular}{|c|c|c|c|c|c|c|}
\hline \multirow{2}{*}{ مستوى الدلادة } & \multicolumn{2}{|c|}{ قيمة مريع كاي ب } & \multirow{2}{*}{ القيم التريوية } & \multicolumn{2}{|c|}{ الجنس } & \multirow{2}{*}{ ل لمجموع } \\
\hline & الجدولية & المحسوية & & إناث & ذكور & \\
\hline \multirow{15}{*}{ مستوى دلالة عند } & \multirow{15}{*}{ TrGTTY } & \multirow{15}{*}{$r \varepsilon, 09 r$} & المساعدة والتعاون & 19 & rr & $\varepsilon r$ \\
\hline & & & حب العمل وتحمل & $\wedge$ & 1. & 11 \\
\hline & & & الحق والعدل & 0 & v & ir \\
\hline & & & الصداقة & 10 & vo & 9. \\
\hline & & & احترام الآخرين & r. & $\leq 0$ & 10 \\
\hline & & & تقدير العلم & $v$ & $\checkmark$ & $1 \varepsilon$ \\
\hline & & & الامانة & 9 & $1 \varepsilon$ & $r$ r. \\
\hline & & & النظافة & $r$ & r & 0 \\
\hline & & & حب الوطن & 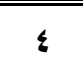 & 1 & 0 \\
\hline & & & التسامح & 17 & $r$. & $m q$ \\
\hline & & & الصبر الصبر & rA & $\varepsilon \wedge$ & VI \\
\hline & & & اطاعة الوالاين & 1 & . & 1 \\
\hline & & & الحفاظ على البيئة & 1 & . & 1 \\
\hline & & & الثجاعة والاعتماد على & $\leqslant 1$ & $\varepsilon r$ & $\wedge \varepsilon$ \\
\hline & & & $1 \varepsilon$ & IV & ras & $\varepsilon 79$ \\
\hline
\end{tabular}


وعند استعمال اختبـار (مربع كاب) لإيجاد دلالـة الفروق في مدى إسـهام الالعـاب الالكترونية في ترسيخ القيم التربوية بين الجنسين، اتضح لنا بان قيمة مربع كاي المستخرجة

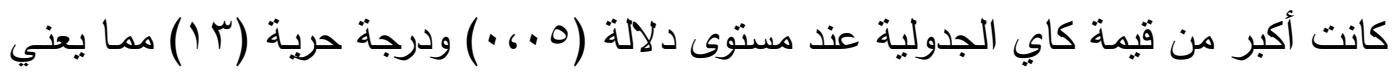
وجود فروق دالة احصائيا بين الجنسين ولصالح الذكور، وبذلك ترفض الفرضية الصفرية وتقبل البديلة. ويمكن تفسير النتيجة الحالية على وفق نظرية (الاعتماد على وسائل الإعلام)

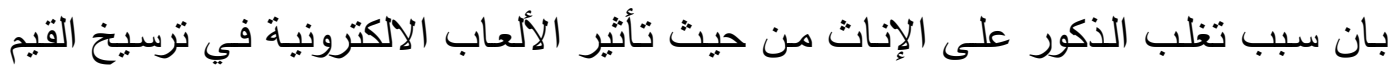
التربوية عليهم، يعود إلى ميل الذكور إلى التماس والبحث عن الراحة والاسترخاء باستمرار،

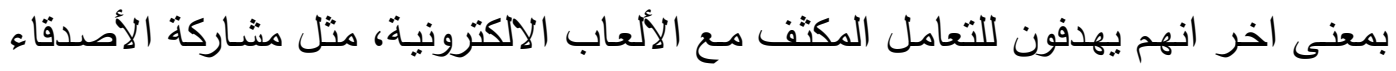

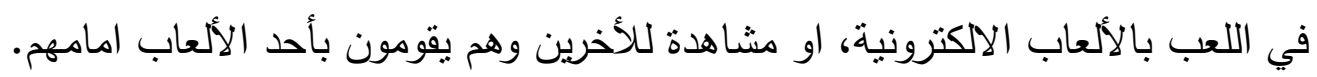

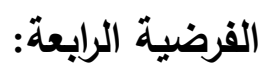

ع-لا توجد فروق ذات دلالة إحصائية بمدى اسهام مواقع التواصل الاجتماعي في ترسيخ القيم التربوية لدى الطفل العراقي تبعا لمتغير الجنس؟ ولقد تم التحقق من الفرضية الرابعة،

وكما في النتائج الموضحة في الجدول (0). الجدول (•) مدى إسهام مواقع التواصل الاجتماعي في ترسيخ القيم التربوية لدى الطقل

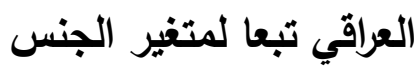

\begin{tabular}{|c|c|c|c|c|c|c|}
\hline \multirow{2}{*}{ مستوى الدلالة } & \multicolumn{2}{|c|}{ قيمة مريع كاي ب } & \multirow{2}{*}{ القيم التريوية } & \multicolumn{2}{|c|}{ الجنس } & \multirow{2}{*}{ المجموع } \\
\hline & الجدولية & المحسوية & & إناث & ذكور & \\
\hline \multirow{11}{*}{ مستوى دلالة } & \multirow{11}{*}{ rYGTYY } & \multirow{11}{*}{ AT,YY } & المساعدة والتعاون & 1. & 1. & $r$. \\
\hline & & & حب العمل وتحمل & Ir & $\wedge$ & r. \\
\hline & & & الحق والعدل & 1 & 10 & 17 \\
\hline & & & الصداقة & 0 & $r$. & ro \\
\hline & & & احترام الآخرين & 11 & IV & rs \\
\hline & & & تقدير العلم & ro & $\Lambda$ & rr \\
\hline & & & الامانة & 11 & $1 \leqslant$ & ro \\
\hline & & & النظافة & Ir & $\wedge$ & $r$. \\
\hline & & & حب الوطن & v & $r$. & TV \\
\hline & & & التسامح & 1. & 1. & $r$. \\
\hline & & & الصبر & $r$ & 11 & rl \\
\hline
\end{tabular}




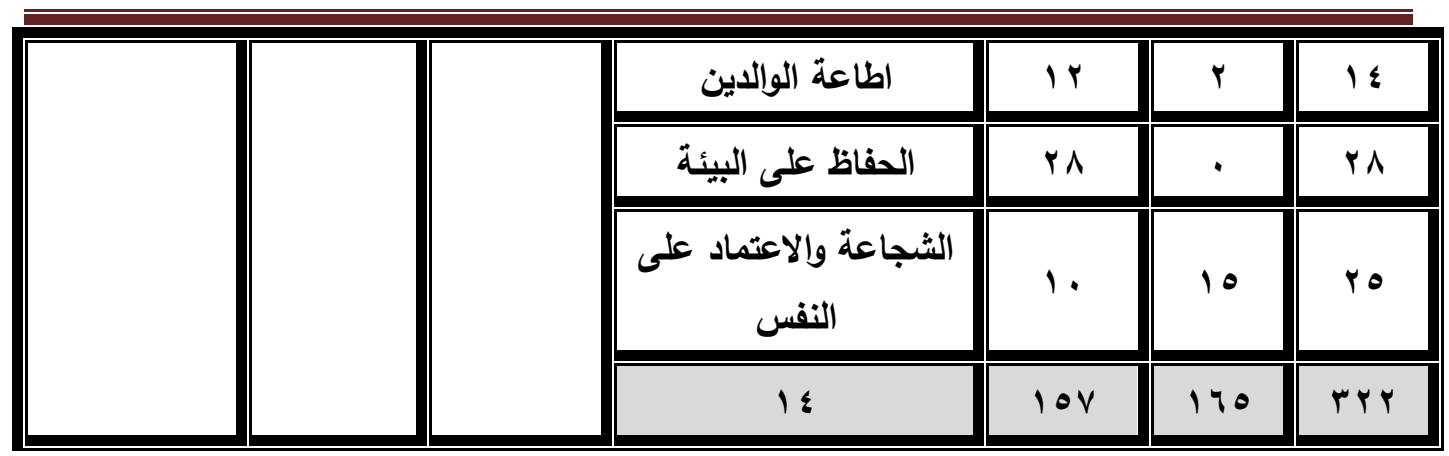

عند استعمال اختبار (مربع كاب) لإيجاد دلالة الفروق في مدى إسهام مواقع التواصل الاجتماعي في ترسيخ القيم التربوبة بين الجنسين، اتضح لنا بان قيمة مربع كاي المستخرجة

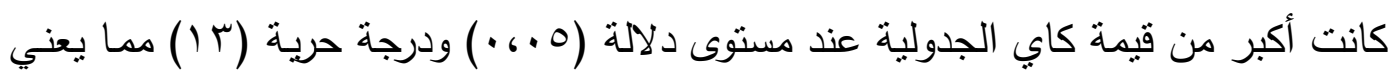

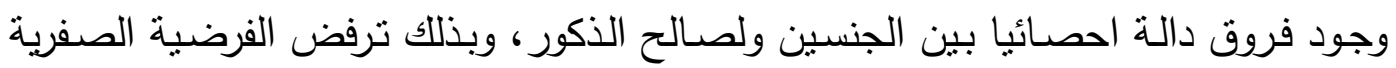

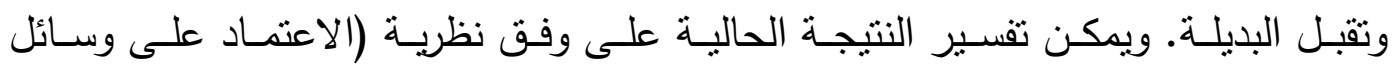

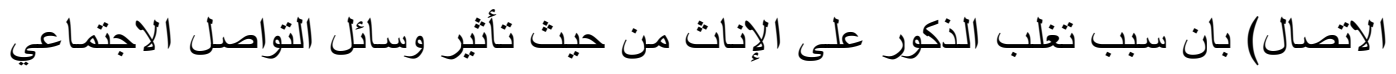

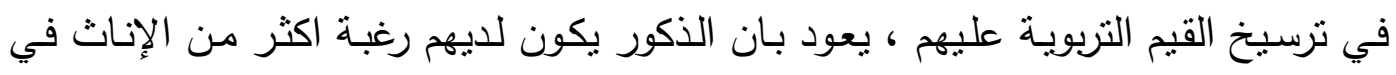

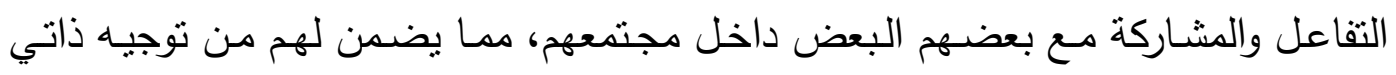
باتجاه القرارات المناسبة، على سبيل المثال المشاركة السياسية او الاجتماعية، كذللك التوجيه

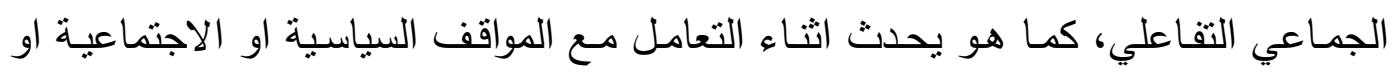
التعليمية المتطورة او الجديدة او الطارئة.

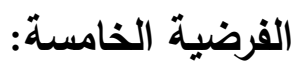
0- لا توجد فروق ذات دلالة إحصائية بمدى اسهام عمليات البحث في ترسيخ القيم التربوية

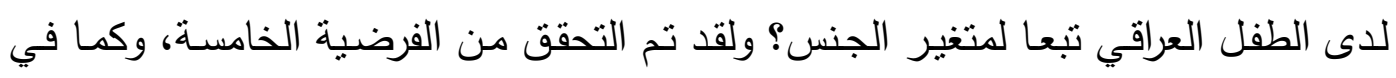
النتائج الموضحة في الجدول (T). الجدول (7) مدى إسهام عمليات البحث في ترسيخ القيم التربوية لاى الطقل العراقي تبعا لمتغير الجنس

\begin{tabular}{|c|c|c|c|c|c|c|}
\hline \multirow{2}{*}{ مستوى } & \multicolumn{2}{|c|}{ قيمة مريع كاي r } & \multirow{2}{*}{ القيم التريوية } & \multicolumn{2}{|c|}{ الجنس } & \multirow{2}{*}{ المجموع } \\
\hline & الجدولية & المحسوية & & إناث & ذكور & \\
\hline \multirow{4}{*}{ مستوى دلالة } & \multirow{4}{*}{ TYGTYY } & \multirow{4}{*}{$r \Lambda_{6} \leqslant v 1$} & المساعدة والتعاون & $r$. & 9 & rq \\
\hline & & & حب العمل وتحمل & 17 & Ir & rA \\
\hline & & & الحق والعدل & $\Lambda$ & 9 & IV \\
\hline & & & الصداقة & 7 & 11 & $r \varepsilon$ \\
\hline
\end{tabular}




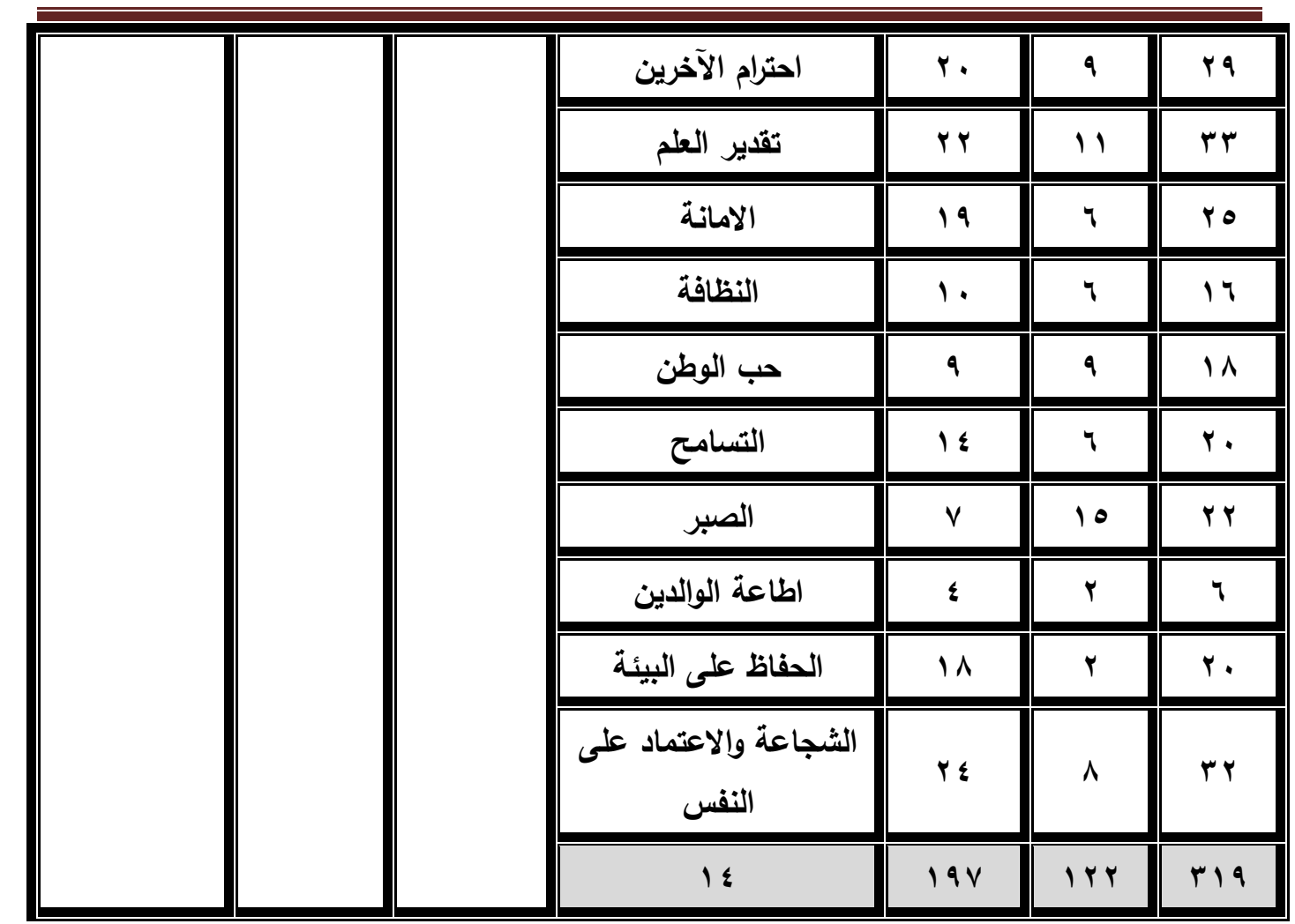

عند استعمال اختبار (مربع كاب) لإيجاد دلالة الفروق في مدى إسهام عمليات البحث

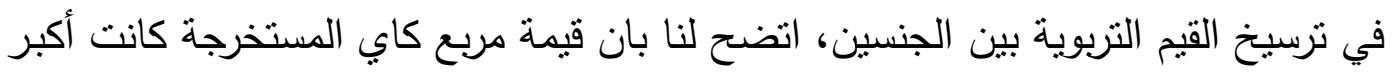

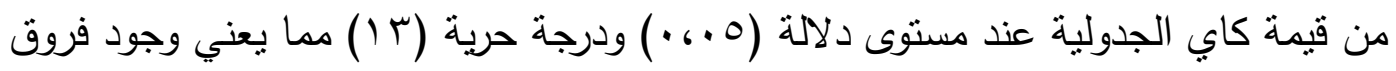
دالة احصائيا بين الجنسين ولصالح الإناث، وبذللك ترفض الفرضية الصفرية وتقبل البديلة.

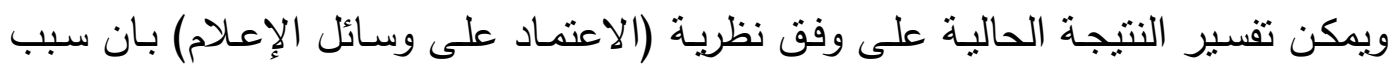

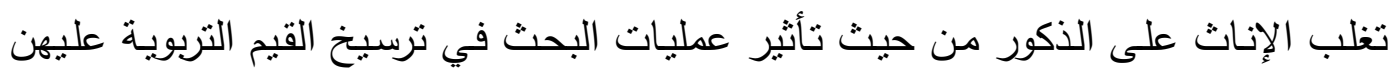

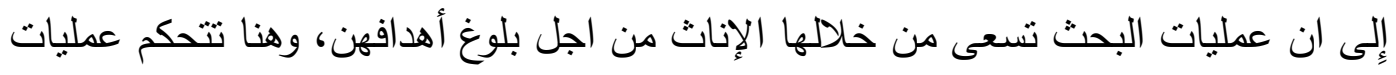

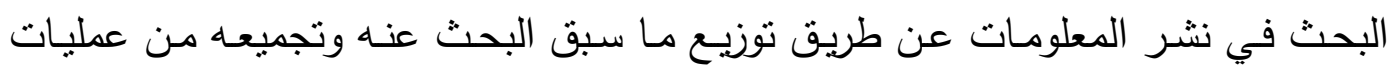

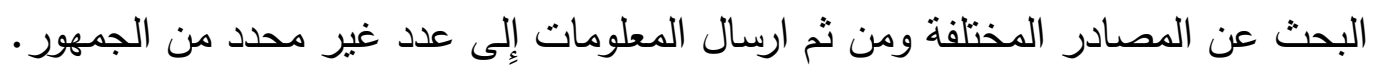

$$
\text { ثانيا-تفسير نتائج البحث: }
$$

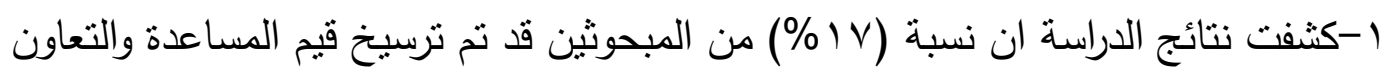
لديهم من خلال اطلاعهم على الصحف والمجلات، ومن ثم جاءت قيمة احترام الآخرين

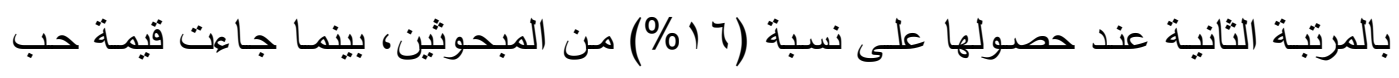

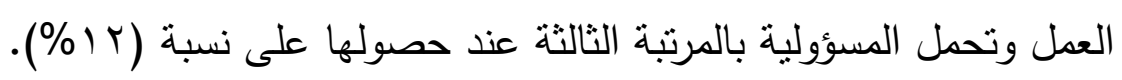

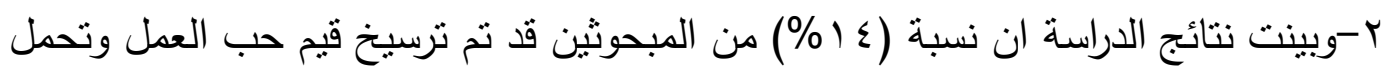

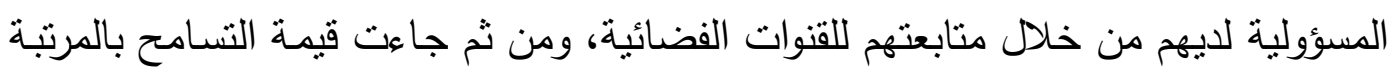


الثانية عند حصولها على نسبة (1 (1\%) من المبحوثين، بينما جاءت قيمة المساعدة والتعاون بالمرتبة الثالثة عند حصولها على نسبة (• (1\%).

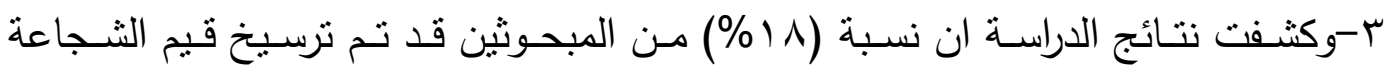

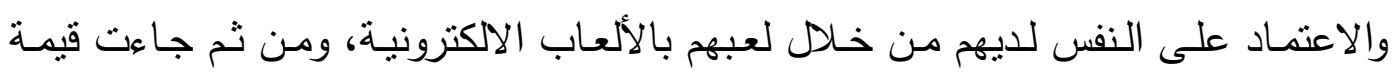

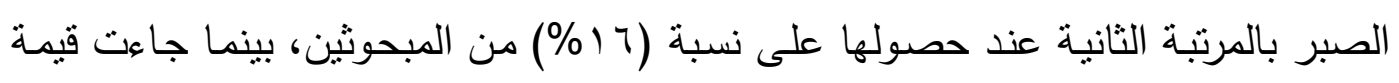

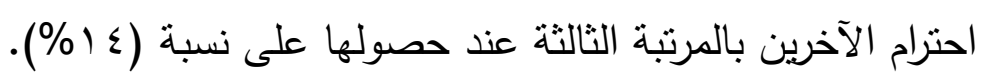
ع-كما وكثفت نتائج الدراسة ان نسبة (• (1\%) من المبحوثين قد تم ترسيخ قيمة تقدير العلم

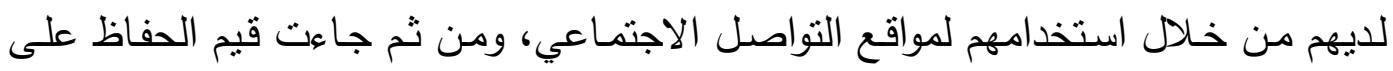
البيئة واحترام الآخرين بالمرنبة الثانية عند حصولهما على نسبة (9 \% من من المبحوثين، بينما

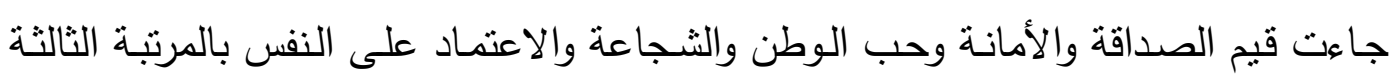
عند حصولها على نسبة (1\%). ه-وأوضحت نتائج الدراسة ان نسبة (• ( \% م) من المبحوثين قد تم ترسيخ قيمة تقدير العلم

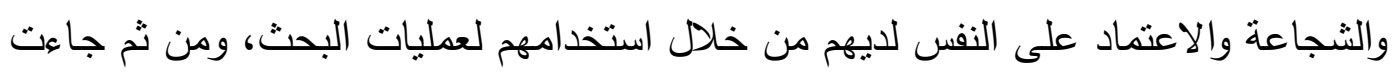

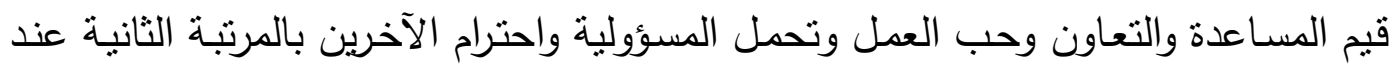
حصولها على نسبة (9\%) من المبحوثين، بينما جاءت قيم الصداقة والأمانة بالمرتبة الثالثة

$$
\text { عند حصولهما على نسبة (1/\%). }
$$

؟-أكدت نتيجة الفرضية الأولى بانه ليس هنالك تأثير لدور للصحف والمجلات في ترسيخ القيم التربوية لدى الطفل العراقي تبعا للجنس.

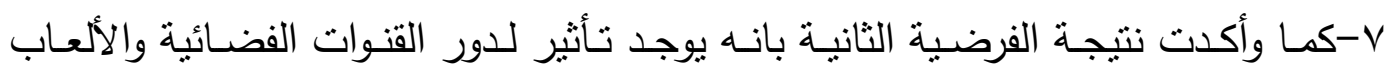

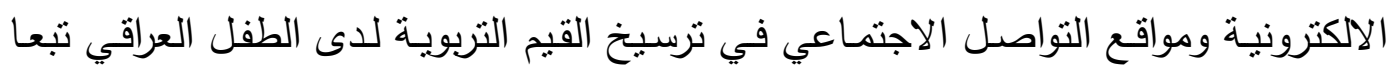

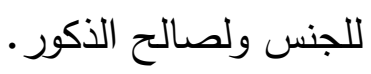

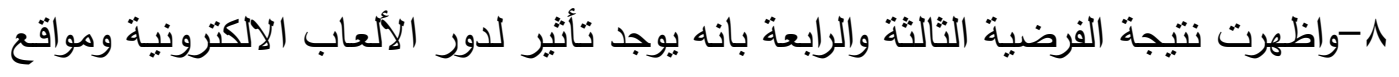

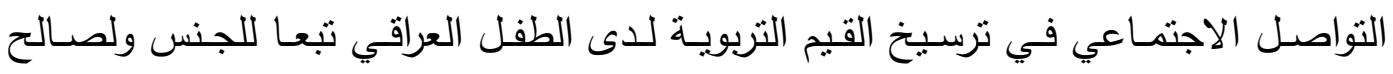
الذكور 9-وأنثارت نتيجة الفرضية الخامسة بانه يوجد تأثير لدور عمليات البحث في نرسيخ القيم التربوية لدى الطفل العراقي تبعا للجنس ولصالح الإناث.

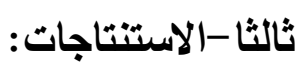

1-هنالك تأثثر كبير لدور الصحف والدجاتلات في ترسيخ القيم التربوية لدى الطفل العراقي. ץ-ليس هنالك تأثثر للجنس تبعا لدور الصحف والمجلات في ترسيخ القيم التنبويـة لاى الطفل العراقي. 
r-هنالك تأثير للجنس تبعا لدور القنوات الفضائية والألعاب الاككترونية ومواقع التواصل الاجتماعي

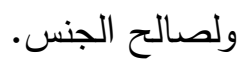
ع-هناللك تأثير للجنس تبعا لدور عمليات البحث ولصالح الاناث.

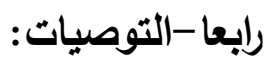

1-توصي الباحثة بان على مؤسسات التعليم العالي إقامة المؤتمرات والندوات التي تهدف إلىى

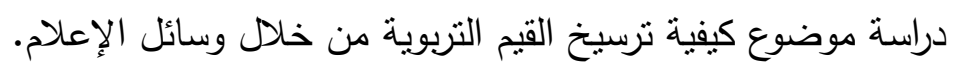

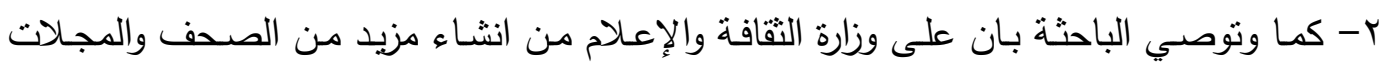

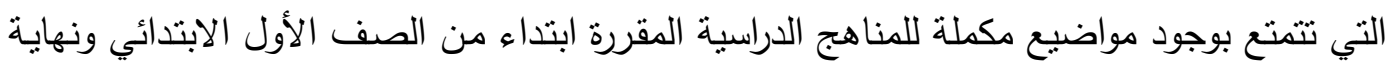

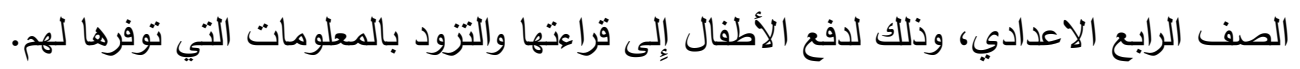

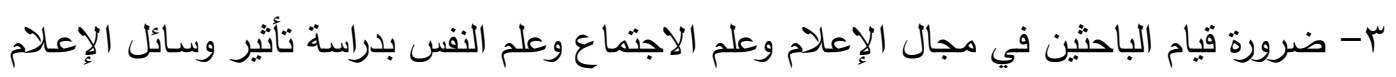
على سلوك وشخصية الطفل العراقي. خامسا-المقترحات: - ( 1-إجراء دراسة مماتلـة على عينة من المرحلة الابتدائية من الصف الأول الابتدائي إلى الصف

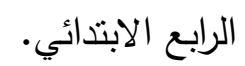

ץ- إجراء دراسـة تهدف معرفة تأثثر وسـائل الإعـلام على تتميـة التفكير الإيجابي لدى الطفل العراقي. r- إجراء دراسة تهدف معرفة علاقة وسائل الإعلام باتجاهات الأطفال نحو اهتماماتهم الدراسية. ع - بناء برنامج إعلامي لتوجيه الأطفال نحو الاستخدام الجيد لوسائل الإعلام.

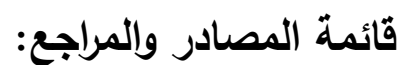

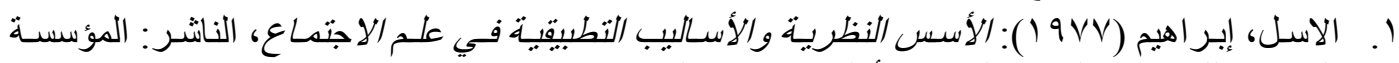

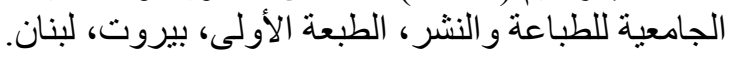

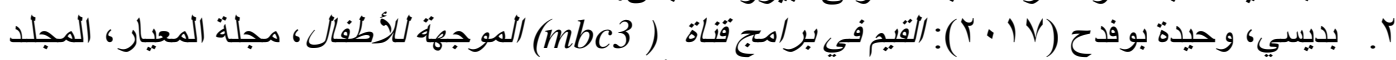

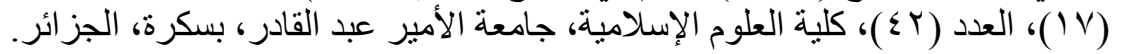

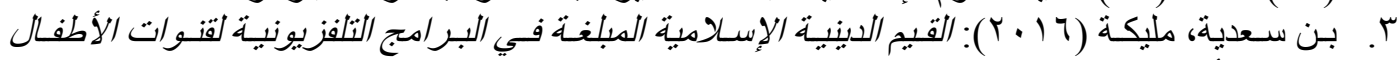

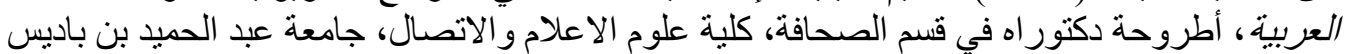

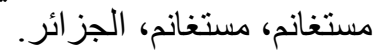

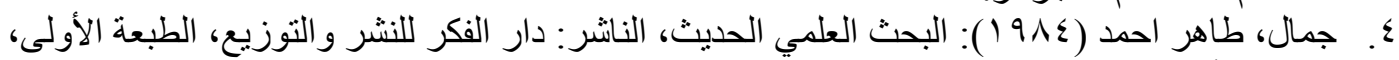

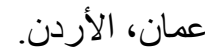

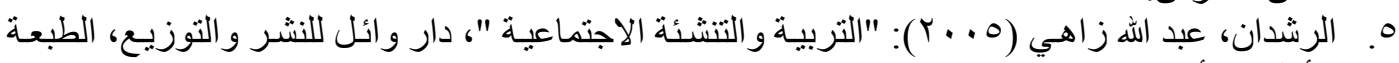

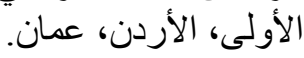

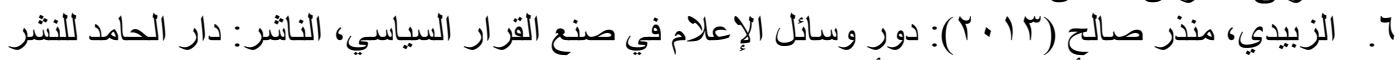
و التوزيع، الطبعة الأولى، عمان، الأردن.

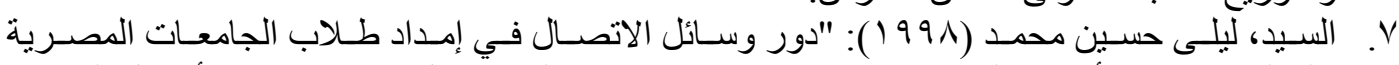

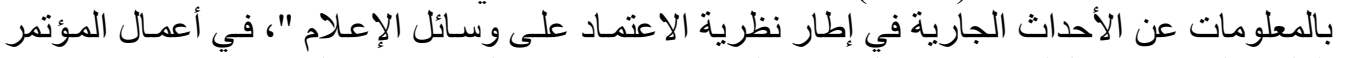

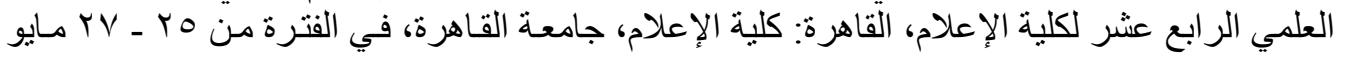

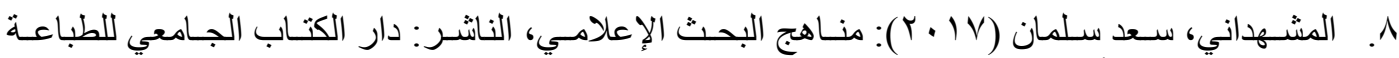
و النشر، الطبعة الأولى، دبي، الامارات العربية. 


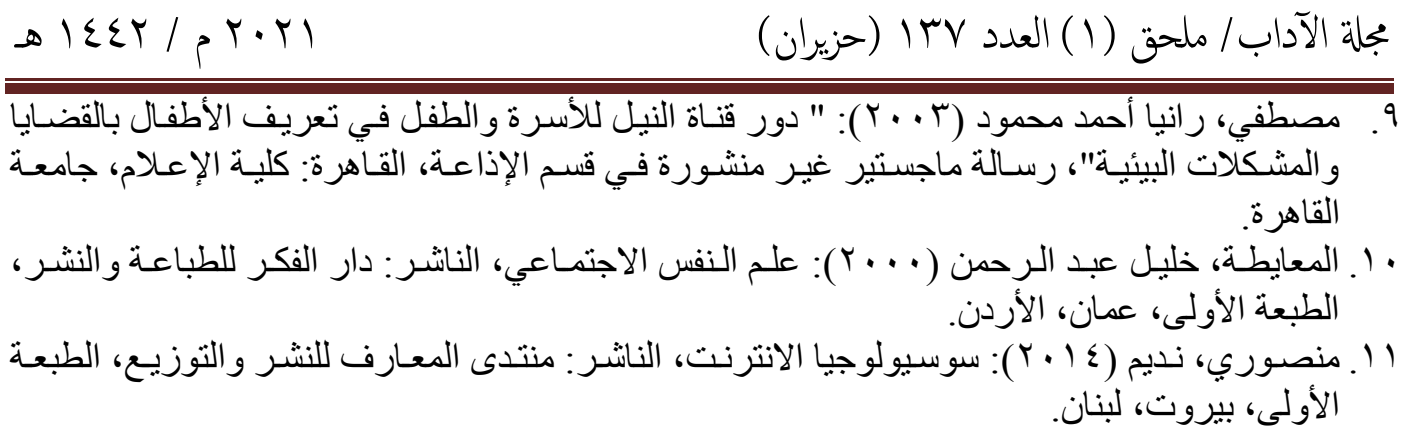

12. Loges. W. E. (1994): "Canaries in The Coal Mire ‘Perception of Threat and Media system Dependency Relations" ‘Communication Research ‘(Vol. 21, 751,1).

\section{References:}

1. Al-Asl, Ibrahim (1977): Theoretical Foundations and Applied Methods in Sociology, Publisher: University Institution for Printing and Publishing, First Edition, Beirut, Lebanon.

2. Bdesi ,Wahida Boufadah (2017): Values in the programs of mbc3 channel for children, Al Maqar Magazine, Volume (17), Issue (42), College of Islamic Sciences, Prince Abdelkader University, Biskra, Algeria.

3. Ben Saadia, Malika (2016): Islamic religious values communicated in television programs for Arab children's channels, $\mathrm{PhD}$ thesis in the Department of Journalism, Faculty of Information and Communication Sciences, Abdelhamid Ben Badis Mostaganem University, Mostaganem, Algeria.

4. Jamal, Taher Ahmad (1984): Modern Scientific Research, Publisher: Dar Al Fikr for Publishing and Distribution, First Edition, Amman, Jordan.

5. Al-Rashdan, Abdullah Zahi (2005): "Education and Socialization", Dar Wael Publishing and Distribution, First Edition, Jordan, Amman.

6. Al-Zubaidi, Munther Salih (2013): The Role of the Media in Political Decision-Making, Publisher: Al-Hamid House for Publishing and Distribution, First Edition, Amman, Jordan.

7. El-Sayed, Laila Hussein Mohamed (1998): "The role of the means of communication in providing Egyptian university students with information about current events within the framework of the theory of reliance on the media," in the works of the fourteenth scientific conference of the Faculty of Mass Communication, Cairo: Faculty of Mass Communication, Cairo University, in the period 25-27 May 1998.

8. Al-Mashhadani, Saad Salman (2017): Media Research Methods, Publisher: Dar University Book for Printing and Publishing, First Edition, Dubai, UAE.

9. Mustafa, Rania Ahmed Mahmoud (2003): "The role of the Nile Channel for the family and children in introducing children to environmental issues and problems", unpublished master's thesis in the Department of Broadcasting, Cairo: Faculty of Information, Cairo University.

10. Al-Ma`aytah, Khalil Abdul Rahman (2000): Social Psychology, Publisher: Dar Al-Fikr for Printing and Publishing, First Edition, Amman, Jordan.

11. Mansouri, Nadim (2014): Internet Sociology, Publisher: Knowledge Forum for Publishing and Distribution, First Edition, Beirut, Lebanon.

12. Loges. W. E. (1994): "Canaries in The Coal Mire 'Perception of Threat and Media system Dependency Relations" ‘Communication Research ‘(Vol. 21, $751,1)$. 